\title{
Meeresalgen von Helgoland: Zweite Ergänzung
}

\author{
P. Kornmann (F) \& P.-H. Sahling \\ Biologische Anstalt Helgoland (Meeresstation); Postfach 180, 27483 Helgoland *
}

\section{Allgemeiner Teil: Hundert Jahre Meeresbotanik in -Helgoland - ein Rückblick}

(ABSTRACT: Marine algae of Helgoland: Second supplement. This investigation complements two previous publications by Kornmann \& Sahling $[1977,1983]$. The paper summarizes floristic changes that have taken place in the marine macroalgal flora of Helgoland, North Sea, over the past 100 years. Moreover, taxonomical and, partly, life history data are given on 5 genera of green algae, e.g. Ulva, including the description of a new species, Ulva tenera; 5 genera of brown algae, e.g. Fucus ceranoides, Sargassum muticum, both species being new records for Helgoland; and 6 genera of red algae, e.g. Porphyra; Mastocarpus stellatus, which is also a new record for Helgoland.) *

\section{EINLEITUNG}

Das hundertjährige Bestehen der Biologischen Anstalt auf Helgoland (seit 1892) ist Anlaß für diesen Rückblick. Während dieser Zeit ist die Naturlandschaft der Insel zu einer Kulturlandschaft geworden. Als Kuckuck 1890 seine Beobachtungen begann, war Helgoland noch allseitig dem Meer und seiner Strömung sowie der Brandung ausgesetzt. Veränderungen des Lebensraumes führten zusammen mit klimatisch bedingten Ursachen zu erheblichen Veränderungen der Algenflora. Darüber wird getrennt in den Abschnitten 2 und 3 berichtet. Tendenzen der Veränderungen der Algenvegetation werden in Abschnitt 4 analysiert.

Über die im Dienste der Biologischen Anstalt tätigen Botaniker und einen Teil ihrer Arbeiten haben schon Mollenhauer \& Lüning (1988) berichtet; Namen und Lebensdaten sind in chronologischer Folge in Abschnitt 3 einbezogen.

\section{VERÄNDERUNGEN DES LEBENSRAUMES}

Um den stetigen Substanzverlust der Insel aufzuhalten, wurde schon $1904 \mathrm{mit}$ Uferschutzmaßnahmen an der Südwestseite begonnen und eine Schutzmauer aus Beton, Basalt und Granit in der Zeit von 1911 bis 1927 erstellt. Damit war zuerst der Buntsandsteinfelsen selbst als Substrat im oberen Eulitoral und der Spritzzone (Supralitoral) verloren gegangen; an seine Stelle war hartes Gestein getreten. Heute ist der ursprüngliche Zustand nur noch an einigen vorspringenden Felsabschnitten wie dem Lummenfelsen erhalten geblieben.

\footnotetext{
- Adressat für Korrespondenz ist Frau Hilde Kornmann; Adresse wie oben

* Peter Kornmann died on 20th August 1993. The 'Abstract' was written by the Editors 
Ein starker Eingriff in die Struktur des Felssockels war der Bau des Marinehafens in der Zeit von 1908 bis 1916. Damals wurde das Hafengelände auf den Klippen der südlichen Abrasionsterrasse aufgeschüttet. Bei der Sprengung der Hafenanlagen 1920-1922 blieben nur die oberen $450 \mathrm{~m}$ der Westmole und $500 \mathrm{~m}$ der Ostmole erhalten.

Die nachhaltigsten Veränderungen erbrachten jedoch der 1934 begonnene Wiederaufbau der Hafenanlagen und der Ausbau Helgolands zur Seefestung, der während des Krieges abgebrochen wurde. Dabei wurde das Unterland Nordost aufgespült, zugleich entstand der Hafen vor der Biologischen Anstalt. Durch eine lange Mole nördlich der "Langen Anna" wurde die Abrasionsterrasse in das heutige SW-Felswatt und das NOFelswatt geteilt; die unterschiedlichen hydrographischen Bedingungen dieser beiden Exkursionsgebiete prägen auch den jeweiligen Charakter ihrer Algenbesiedelung.

Zwischen den langen Molen der Düne wurde das frühere Klippenfeld des Kalbertans mit Sand bedeckt. Damit ging ein zu Kuckucks Zeiten ergiebiger Fundort für einige Besonderheiten der Helgoländer Algenflora verloren. (Paul Kuckuck wirkte als erster Kustos für Botanik 1892 bis 1914 in Helgoland.)

Noch einmal wurden die Hafenmolen nach dem Zweiten Weltkrieg zerstört und nach der Freigabe der Insel (1952) in der heutigen Form wieder aufgebaut.

Durch die Kunstbauten ist ein reich gegliederter Lebensraum in der supra- und eulitoralen Zone entstanden. Die Stufen auf der Innenseite der Hafenmauern und auch der Dünenmolen sind zum Teil zugänglich; ihre ganz verschiedene geographische Exposition schafft zugleich unterschiedliche Bedingungen in bezug auf Wellenschlag, Belichtung oder Austrocknung und damit zusätzliche Varianten für die Algenbesiedelung.

\section{VERÄNDERUNGEN DER ALGENFLORA}

Der laufende Wandel des Lebensraumes ist nicht ohne Einfluß auf die Algenvegetation geblieben; er prägt sogar maßgeblich ihr heutiges Bild. Die wertvollste Grundlage für feststellbare Veränderungen der Algenflora ist das glücklicherweise erhalten gebliebene Herbarium von Paul Kuckuck (1866-1918); die meisten Exsikkate wurden zwischen 1892 und 1900 gesammelt. Eine Liste der braunen und roten Algen von Helgoland (Reinke, 1891) weist keine anderen als die in Kuckucks Herbarium enthaltenen Arten auf. Vegetationsschilderungen in zwei kurzen Beiträgen (Kuckuck, 1897a, b) tragen nicht zur Ergänzung der Herbarangaben bei.

Eine große Lücke klafft in der Zeit bis zum Ende der 50er Jahre. Eine 1925 erschienene Arbeit von Wilhelm Nienburg (1882-1932) gibt ebenso wie eine von O. C. Schmidt (1928) nur eine recht allgemein gehaltene Darstellung über die Algenvegetation; es werden die häufigen Arten genannt, die mit wenigen Ausnahmen auch heute noch verbreitet sind. Alle Aufzeichnungen von O. C. Schmidt über Exkursionen in den $20 \mathrm{er}$ und 30er Jahren sind verloren gegangen, ebenso auch das Herbarium von Ernst Schreiber (1896-1980) und unsere eigenen Sammlungen aus der Zeit vor 1939. So gründet sich ein Vergleich der jetzigen Algenflora mit der vor 100 Jahren im wesentlichen auf das Herbarium von Kuckuck und unsere laufenden Beobachtungen ab 1959 nach der Rückkehr an die wieder auf Helgoland errichtete Biologische Anstalt. Die Unterschiede sind erheblich; eine ganze Reihe von Arten ist verschwunden, aber es ist auch eine größere Anzahl von Algen hinzugekommen. Dabei sollen in den beiden nächsten Abschnitten nur die großen oder anderweitig bemerkenswerten Algen berück- 
sichtigt werden. Die Gründe für solche Veränderungen der Algenflora sind im allgemeinen nicht bekannt, es sei denn, daß Algen einen neuen Lebensraum besiedeln konnten.

Stark zugenommen hat sicherlich die bei Helgoland produzierte Algenbiomasse als Folge der zunehmenden Eutrophierung des Meerwassers (Hickel et al,, 1993), so daß in dem nährstoffreichen Wasser in den letzten Jahren Porphyra-Thalli zu etwa $1 \mathrm{~m}$, Ulva sogar bis zu $5 \mathrm{~m}$ Länge heranwachsen konnten (s. u.).

\subsection{GRÜNALGEN}

Am stärksten haben sich die Grünalgen unter den veränderten Standortbedingungen, der Eutrophierung und sicherlich auch klimatischen Veränderungen ausgebreitet; dies gilt für ihre Anzahl als auch ihre Biomasse. Mit dem heutigen Aspekt verglichen muß die Grünalgenflora zu Kuckucks Zeiten geradezu kümmerlich gewesen sein. Allen Arten, die heute die Uferschutzmauern besiedeln, fehlte das geeignete harte Substrat. Zu ihnen gehören die Prasiola-Arten, wobei Prasiola calophylla stellenweise $P$. stipitata überwiegt. Rosenvingiella polyrhiza und R. constricta (seit 1973) haben auf den Molen ihren Platz. Capsosiphon fulvescens wie auch Blidingia minima und B. marginata fehlen im Herbarium Kuckuck; sie wachsen im oberen Litoral der Mauern.

Festsitzende Pflanzen der "Wanderalge" Codium fragile wurden zuerst 1930 beobachtet (O. C. Schmidt, 1936). Die sich zu dieser Zeit nach Osten ausbreitende Art wurde auch 1932 in List/Sylt auf lebenden Austern gefunden. Chaetomorpha tortuosa hat sich seit 1967 auf dem Nordost-Felswatt eingebürgert.

Anfang der $60 \mathrm{er}$ Jahre überraschte uns die Vielfalt der früher nicht vorhandenen Monostroma-Arten (im weiteren Sinne), die Gegenstand entwicklungsgeschichtlicher Untersuchungen waren (Kornmann \& Sahling, 1962b). Die einzige im Herbarium Kukkuck verwahrte Art, $M$. grevillei, ist wenig einheitlich, doch enthalten die Exsikkate keine anderen leicht erkennbaren Arten. Morphologisch nicht unterscheidbar, könnten sie mit $M$. arcticum vermischt sein, die sich nur ungeschlechtlich vermehrt. Schlanke geschlossene Schläuche bis zu $20 \mathrm{~cm}$ Länge, die an M. saccodeum/cylindraceum erinnern, sind uns zuerst 1960 und 1961 begegnet.

Monostroma leptodermum, seit 1961 immer wieder gefunden, wurde schon nach einer 1934 gesammelten Probe von O. C. Schmidt (1938) als neue Art, M. helgolandicum, beschrieben. M. undulatum, 1954 und 1955 erstmals bei kurzen Besuchen Helgolands beobachtet, trat seit den 60er Jahren immer wieder massenhaft auf. Dasselbe gilt für Urospora wormskioldii, deren dicke Fäden dem Substrat an der Niedrigwasserlinie wie gekämmt anliegen.

Erst seit wenigen Jahren ist uns eine kleine zarte Ulva-Art aus dem oberen Eulitoral bekannt, über die weiter unten ausführlich berichtet wird.

\subsection{BRAUNALGEN}

Nicht mehr vorhandene Arten

Cutleria multifida (Sm.) Grev.

Schon vor der Zeit Kuckucks ist eine bemerkenswerte Alge der Helgoländer Flora verschwunden; sie wurde noch von Wollny (1886) als Seltenheit angegeben: Cutleria 
multifida. Ihr widmete Kuckuck (1894) eine ausführliche Untersuchung. Der Sporophyt, Aglaozonia parvula (Grev.) Zanard., war im Nordhafen eine der häufigsten Pflanzen. Von ihm ausgehend, erhielt Kuckuck in Aquariumskulturen Cutleria-Pflänzchen bis zu $1 \mathrm{~cm}$ Länge. Inzwischen ist auch Aglaozonia verschwunden. Einzelne Krusten wurden noch in den $30 \mathrm{er}$ Jahren im Nordhafen gedredscht.

Leathesia difformis (L.) Aresch.

Noch in den 30er Jahren war diese Art nicht selten. Sie gehörte sogar nach O. C. Schmidt (1938, S. 10) "zu den Formen, die wie Bryopsis plumosa, Cladophora Sonderi oder Leathesia gerade in den letzten Jahren ihr Helgoländer Areal stark ausweiten."

Dictyota dichotoma (Huds.) Lamour.

An ihrem früheren Standort im Litoral ist sie verschwunden, aber sublitoral wieder aufgetreten. Darüber wird in dem speziellen Teil ausführlich berichtet.

\section{Früher nicht vorhandene Arten \\ Himanthalia elongata (L.) S. F. Gray}

Die an den atlantischen Küsten Europas verbreitete Alge war vorübergehend Gast unserer Algenflora; sie könnte daher zumindest zeitweise unter den hier gegebenen Bedingungen existieren. Ein kleiner Standort an einer Stelle der zerstörten Mauer fiel der starken Vereisung im Winter 1962 zum Opfer. Hier war also die gelegentlich tiefe Temperatur der begrenzende Faktor.

Ende der 50er Jahre trieben große Mengen von Himanthalia bei Helgoland an und gelangten auch in den Südhafen. Dort wurden am 21. Juli 1960 zahlreiche napfförmige Thalli auf einer Mauerstufe im Niveau von Fucus spiralis und F. serratus gefunden. Leider ging dieser Fundort durch darauf abgelagerte Betonquader verloren, noch bevor Rezeptakel gebildet waren.

Sargassum muticum L.

Über diese in den letzten Jahren eingewanderte Alge wird weiter unten ausführlich berichtet.

\subsection{ROTALGEN}

\section{Nicht mehr vorhandene Arten}

Kuckucks Herbarium enthält eine größere Anzahl von Rotalgen, die schon in den 30er Jahren seltener geworden waren. Dazu zählen Helminthocladia, Scinaia und Helminthora. Sie wuchsen nach der Schilderung von Peter Krüß, damals Laborant von Kuckuck, in großer Menge auf dem Kalbertan. Ihr Verschwinden ist nicht nur durch den späteren Verlust dieses Standorts bedingt. Bemerkenswert ist nämlich die Feststellung, daß sich Helminthocladia und Scinaia als kalkbohrende Stadien erhalten haben und daraus im Laboratorium kultiviert werden konnten (Kornmann \& Sahling, 1980). Laurencia pinnatifida ist mit zahlreichen stattlichen Exsikkaten im Herbarium Kuckuck vertreten, aber ebenso wie Jania rubens verschwunden. Beide kamen noch in den 30er Jahren selten auf den Nathurn-Klippen vor, die man damals mit dem Boot erreichte. Diesen Angaben liegen eigene Erinnerungen zugrunde. 
Die seltene und kurzlebige, nur während 4-6 Wochen im August im Sublitoral vorkommende Apoglossum (= Delesseria) ruscifolia (Kuckuck 1894, Fig. 25) ist nicht wieder gefunden worden. Auch Chondria dasyphylla, durch zahlreiche Exsikkate von dem Felswatt vor dem Lummenfelsen belegt, ist uns niemals begegnet. Antithamnion cruciatum haben wir vergeblich gesucht.

\section{Neu aufgetretene Rotalgen}

\section{Trailliella intricata Batters}

Erst am Ende des vorigen Jahrhunderts wurde Trailliella intricata in Europa eingeschleppt ${ }_{i}$ im Herbarium Kuckuck ist sie mit einem winzigen Exemplar vom 20.8. 1900 vertreten. Der Gametophyt, Bonnemaisonia hamifera, war Ende der 60er Jahre ein vorübergehender, sogar in großer Menge aufgetretener Gast (Kornmann \& Sahling, 1962 a). Trailliella intricata ist der Sporophyt von Bonnemaisonia hamifera.

Phyllophora traillii Holmes ex Batters. Tetrasporophyt = Erythrodermis allenii.

Diese Art wurde von Kuckuck nicht beobachtet, sie wäre ihm in dem häufig untersuchten Dredschmaterial sicher nicht entgangen. Mit dem nötigen Vorbehalt ist diese, von Lüning (1970) in allen Tiefenstufen des Sublitorals gesammelte Alge (Abb. 112 bei Kornmann \& Sahling, 1977) als neu für Helgoland anzusehen.

Mastocarpus stellatus (Stackh. in With.) Guiry syn. Gigartina stellata (Stackh.) Batters und Polysiphonia lanosa (L.) Tandy, syn. P. fastigiata

sind seit einigen Jahren eingebürgert. Über die näheren Umstände ihrer Ansiedlung wird in dem speziellen Teil ausführlich berichtet.

\section{TENDENZEN DER VERÄNDERUNGEN}

Wahrscheinlich in weiträumigen, klimatologisch-hydrographischen Ursachen begründet, lassen die Veränderungen der Algenvegetation Helgolands zwei Tendenzen klar erkennen:

(1) In der ersten Jahrhunderthälfte ist eine Reihe von Arten verschwunden, die wir heute in dem wärmeren Teil der kaltgemäßigten Florenregion antreffen. Die Algenliste von Roscoff, Bretagne (Feldmann, 1954), enthält alle in Abschnitt 3.3 aufgeführten, nicht mehr bei Helgoland vorkommenden Rotalgen: Helminthora divaricata, Helminthocladia calvadosii, Scinaia furcellata, Laurencia pinnatifida, Jania rubens, Chondria dasyphylla und Apoglossum ruscifolium.

(2) In der zweiten Hälfte des Jahrhunderts sind bei Helgoland eine ganze Reihe von Algen erstmals beobachtet worden, die im nördlichsten Teil der kaltgemäßigten Region wachsen. Für Jaasund (1965) ist es bemerkenswert, daß vier arktische MonostromaArten bei Helgoland vertreten sind. Moestrup et al. (1975) weisen mit dem erstmaligen Fund von M. undulatum bei Hirsholmen (Kattegat Nord) ebenfalls auf das Vorkommen dieser typischen Kaltwasserform bei Helgoland hin.

Die Hinweise aus der Literatur werden durch eigene Beobachtungen ergänzt. Seit der Freigabe der Insel im Jahre 1952 wurde im zeitigen Frühjahr eine für uns heute, mit Pilayella littoralis unverwechselbare Art mitunter in großen Mengen gesammelt. Sie war 
mit Sicherheit vor 1939 nicht vorhanden. In unserer Algenflora von 1977 wurde die in Abbildung 54 als Pilayella spec. bezeichnete Art Pilayella littoralis (Abb. 53) gegenübergestellt (Kornmann \& Sahling, 1977). Inzwischen konnte sie mit der arktischen P. macrocarpa Foslie identifiziert werden (Kornmann, 1990).

In ganz entsprechender Weise stehen sich in der Gattung Rhodomela zwei Arten mit signifikant verschiedenen Merkmalen gegenüber: $R$. confervoides mit Fortpflanzungsorganen an den Zweigenden (Kornmann \& Sahling, 1977, Abb.145) und R. virgata Kjellman (1883), bei der die Fortpflanzungsorgane den Achsen in besonderen Kurztrieben entsprossen (Abb. 146). R. virgata wird in der Literatur nicht allgemein als selbständige Art anerkannt. Auch bei ihr spricht das Vorkommen bei Helgoland in Gesellschaft mit den übrigen arktischen Vertretern sehr zugunsten ihrer Spezifität.

Zwei weitere Arten aus der nördlichen Region der kaltgemäßigten Florenregion sind bei Helgoland als besondere Seltenheiten gefunden worden: Antithamnionella floccosa und Uronema curvata. Über beide Arten wird im speziellen Teil dieser Arbeit ausführlich berichtet.

Das klare Ergebnis: Helgoland ist im Laufe der letzten Jahrzehnte zu einem geographisch abgegrenzten Lebensraum hochnordischer Algen innerhalb der kaltgemäßigten Florenregion geworden. Ein Vergleich mit den vorliegenden hydrographischen Temperaturmeßwerten bei Helgoland (Radach et al., 1990) läßt keinen Zusammenhang erkennen.

\section{Spezieller Teil}

Dieser Teil enthält im wesentlichen eine Aufstellung der nach 1983 (Kornmann \& Sahling, 1983) neu für Helgoland beschriebenen Taxa.

\section{GRÜNALGEN}

\section{Ulva Linné}

Die eingehende taxonomische Bearbeitung der Ulva-Arten an der niederländischen Küste durch Koeman \& van den Hoek (1981) macht eine Revision unserer früheren Angaben über diese Gattung erforderlich. Danach gehört die Ulva-Population im unteren Eulitoral des Helgoländer Felswatts mehrheitlich zu der von ihnen neu beschriebenen Ulva pseudocurvata. Das Vorkommen von Ulva lactuca bei Helgoland ist ebenso unsicher, wie ihre Identifizierung schwierig ist. Eindeutig sind indessen die Merkmale einer kleinen zarten Ulva, die im oberen Eulitoral in Gesellschaft von Blidingia vorkommt. An den nordeuropäischen Küsten ist keine ihr entsprechende Art bekannt.

\section{Ulva pseudocurvata Koeman \& van den Hoek}

Diese Art ist identisch mit der Alge, über die wir 1977 unter dem Namen Ulva curvata eingehend berichtet haben; damals war Ulva pseudocurvata noch nicht beschrieben. Fünf Ulva-Arten kommen in den niederländischen Gewässern vor; zwei von ihnen, Ulva lactuca und U.pseudocurvata bevorzugen die offene Küste; beide 
wachsen im unteren Eulitoral und oberen Sublitoral an Hafenmolen und Seedeichen. Die übrigen drei Arten sind im wesentlichen im Tidenbereich der von der See abgetrennten polyhalinen Gewässer und in Estuarien anzutreffen. $\mathrm{Zu}$ diesen gehört auch die von uns 1977 und schon vorher von anderen Autoren irrtümlich für Helgoland angegebene U. curvata. Die häufig gekrümmte Form des Thallus schien uns die Zuordnung zu dieser Art zu rechtfertigen, jedoch schließt allein schon das rein marine Milieu das Vorkommen von $U$. curvata bei Helgoland aus. Darüber hinaus ist $U$. curvata durch ein leicht erkennbares anatomisches Merkmal eindeutig gekennzeichnet. Als einzige der von Koeman \& van den Hoek (1981) untersuchten fünf Arten hat sie ein hohles Stielchen und ermangelt der kleinzelligen Randflügel. Bei den anderen Arten wird der Stiel von den herablaufenden faserigen Rhizoiden ausgefült, der Thallusrand ist kleinzellig.

Seit 1956 belegen zahlreiche Aufsammlungen unseres Herbariums das Vorkommen von Ulva pseudocurvata bei Helgoland. Sie wächst in großen Mengen im unteren Eulitoral des Felswatts auf felsigem Grund, ist aber auch an schwimmenden Gegenständen wie Pontons oder Bojen überall anzutreffen. Ihre Mannigfaltigkeit in Größe und Form ist sowohl ökologisch wie altersmäßig bedingt. In dem strömenden Wasser des Felswatts sind die Thalli meist schlank, häufig bis $50 \mathrm{~cm}$ lang und 10 bis $15 \mathrm{~cm}$ breit. In ruhigem Wasser sind sie meist kleiner, breit-oval und gelegentlich auch gelappt. Häufig sind die nur wenig faltigen jüngeren Pflanzen leicht gebogen.

Die Mannigfaltigkeit der Form von U. pseudocurvata ergibt sich aus dem Zusammenspiel von Wachstum und wiederholter Fertilisierung während ihrer ganzen Lebensdauer. Pflanzen, die noch nicht geschwärmt haben, sind schlank mit keilförmiger Basis, das Thallusende ist abgerundet (Abb. $1 \mathrm{~A}$ ). Die Schwärmerbildung erfolgt in der apikalen Zone und grenzt sich mit einer scharfen, oft mehr oder weniger unregelmäßigen Linie von dem vegetativen Thallus ab. Der entleerte Thallusabschnitt bleibt häufig als durchsichtige Haut haften und zeigt so die frühere Form der Alge an. Gelegentlich läßt sich an solchen Pflanzen schon die nächste Umwandlungszone makroskopisch erkennen (Abb. 1B). Der vegetative Thallus wächst weiter und verbreitert sich, und das Thallusende wird ausgebuchtet oder lappig. Unter optimalen Wachstumsbedingungen in den Sommermonaten bestehen die großen variablen Thalli oft nur aus einer kleinen keilförmigen Basis mit größeren fertilen oder ausgeschwärmten Flächen; ihr Verlust führt spontan zu erheblichen Formveränderungen. Bei vermindertem Wachstum im Spätherbst werden dagegen die Pflanzen nach einer oder mehreren Fertilisierungen immer mehr auf ihre keilförmige Basis reduziert (Kornmann \& Sahling, 1977, Abb.30).

Bei zahlreichen Pflanzen verbleiben in den entleerten Thallushäuten mehr oder weniger dichte Gruppen von grünen Inseln, die schließlich zu eigenartigen Ringbildungen führen (Abb.2). Mitunter lassen sich solche "Augen" schon in der Umwandlungszone erkennen, andererseits sind sie nicht bei allen Pflanzen vorhanden. Wahrscheinlich liegt hier eine bakterielle oder eine Virusinfektion vor, die bisher offenbar nicht beschrieben ist. In unserem umfangreichen Herbarmaterial seit 1954 waren solche Ringbildungen häufig zu finden. Bewußt wahrgenommen haben wir sie erst im Oktober 1976, als das Algenbuch schon im Druck war.

Unter optimalen Wachstumsbedingungen können Ulva-Thalli riesige Ausmaße erreichen und sind so die größten Algen Helgolands überhaupt. Bis zu $5 \mathrm{~m}$ lange und knapp $1 \mathrm{~m}$ breite Exemplare wurden am 1. August 1991 im Nordostfelswatt gesammelt. Das wochenlang anhaltende Sommerwetter bei entsprechender Erwärmung des ohnehin 


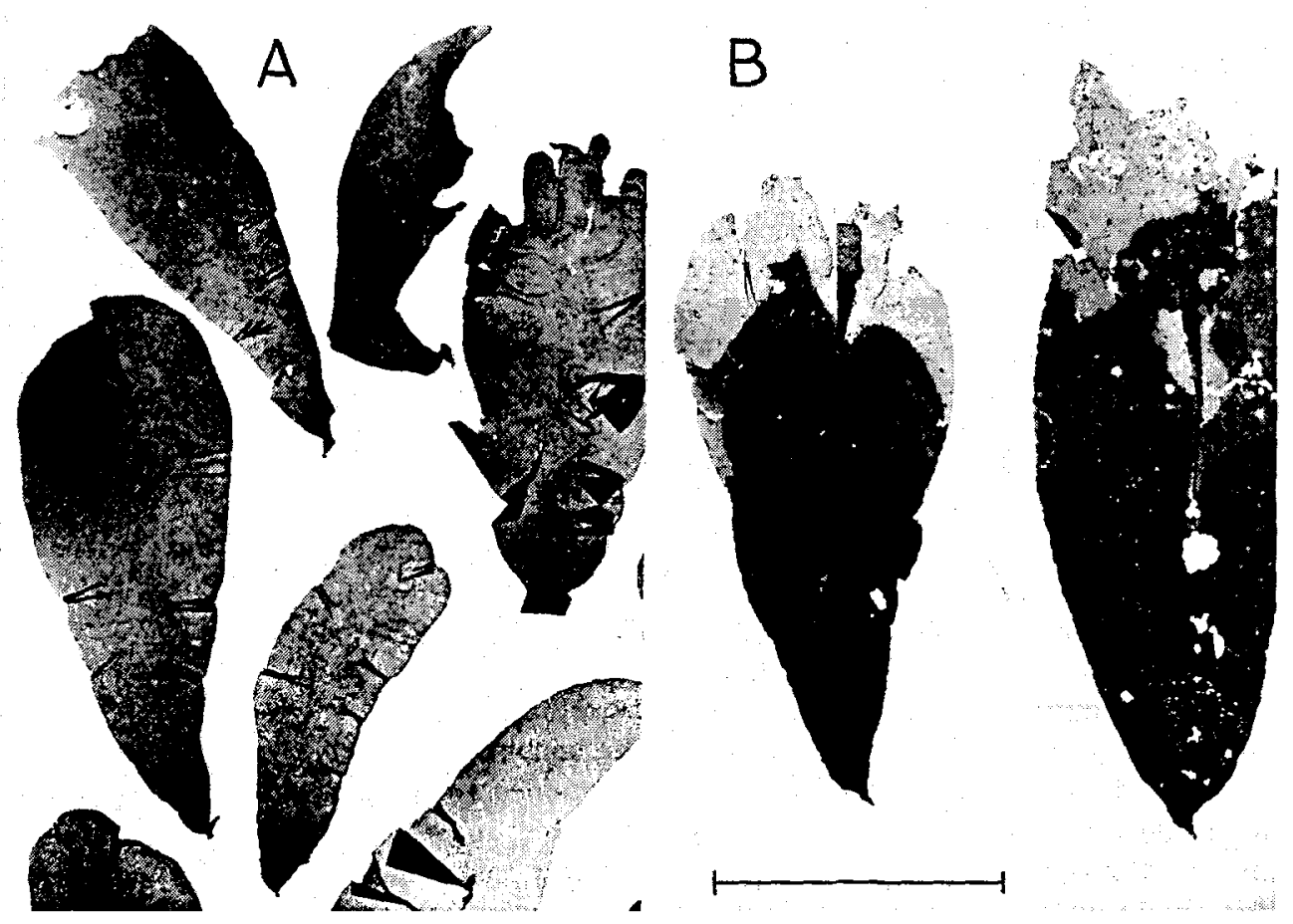

Abb. 1. Ulva pseudocurvata. A: Jüngere, noch nicht fertile, apikal abgerundete Thalli und solche mit unregelmäßigem Ende nach dem Schwärmen. B: Häufig haftet der ausgeschwärmte Teil noch an der Pflanze. Die nächste Umwandlungszone grenzt sich scharf gegen den vegetativen Thallus ab. Maßstrecke: $5 \mathrm{~cm}$

nährstoffreichen Wassers vermag das ungewöhnliche Wachstum zwar nicht zu erklären, war aber doch sicherlich die Voraussetzung dafür. Es ist erstaunlich, daß solche großen Pflanzen auf ihrer kleinen Haftscheibe der - wenn auch nur geringen - Strömung standhielten.

Das Vorkommen von U.pseudocurvata bei Helgoland ist schon lange durch frühere Autoren belegt; die Alge hat bei den Botanikern auch ebenso lange für Verwirrung gesorgt. Zuerst wurde sie von Wollny (1881) als identisch mit der 1845 von Kützing nach Material von Rügen (Ostsee) beschriebenen Phycoseris curvata angesehen. Schiller (1928, Fig. 1) hielt diese "charakteristisch gestalteten" Thalli von "Ulva curvata" für eine neu bei Helgoland aufgetretene Alge und bildete ganz typische Exemplare ab, die alle vom gleichen Fundort stammten. Auch O.C. Schmidt (1938) hielt diese Art für Ulva curvata. Aber schon Kuckuck (1894, Fig. 26) war diese Alge aufgefallen. Unverkennbar stellen die von ihm abgebildeten Exemplare von "Ulva latissima f. nana" fertile Thalli von Ulva pseudocurvata dar, wobei er darauf hinweist, daß die Fertilisierung "in charakteristischer Weise an der oberen peripherischen Zone" erfolgt. Schließlich hat O. C. Schmidt (1936) "Ulva lactuca f. nana" reichlich und gut entwickelt im Herbst 1932 gesammelt und als Ulva kuckuckiana beschrieben. Seinen nur $4 \mathrm{~cm}$ langen und $3-4,5 \mathrm{~cm}$ 

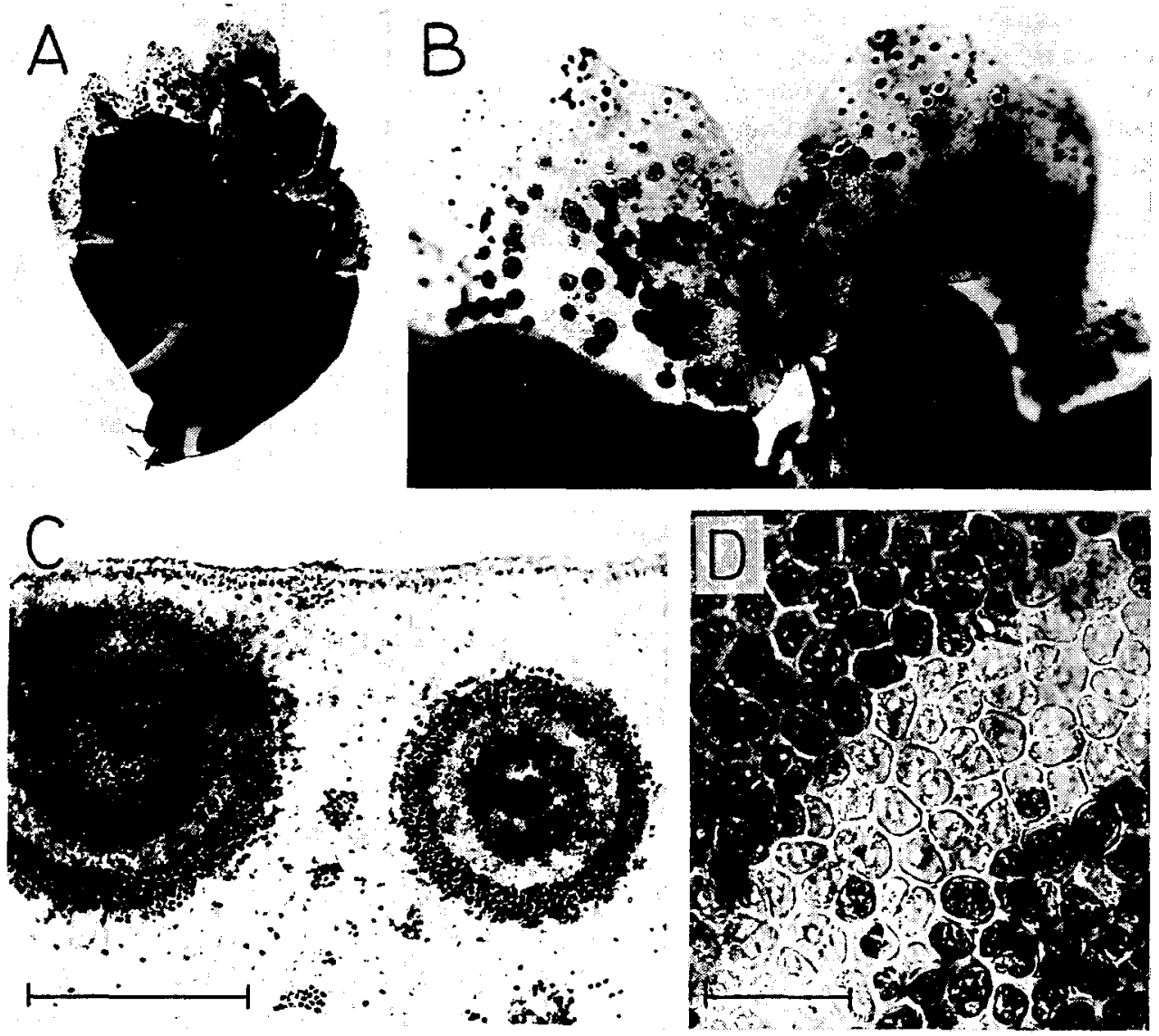

Abb. 2. Ulva pseudocurvata, 10. 10. 1976. A: In der Membran des ausgeschwärmten Thallus verbliebene Punkte und ringförmige Inseln bei natürlicher Größe. B: Ausschnitt vergrößert. C, D: Details bei stärkerer Vergrößerung. Maßstrecken: $C=500 \mu \mathrm{m}_{i} \mathrm{D}=50 \mu \mathrm{m}$

breiten Exemplaren liegen unverkennbar alte, bis auf die Basis reduzierte Thalli von Ulva pseudocurvata zugrunde.

\section{Ulva lactuca}

Zum Schluß soll einer naheliegenden Frage nicht aus dem Wege gegangen werden: Gibt es bei Helgoland auch Ulva lactuca, und wie unterscheidet sie sich von Ulva pseudocurvata? Koeman \& van den Hoek (1981) fanden beide Arten unter denselben ökologischen Bedingungen im euhalinen Bereich an Seedeichen und Hafenmolen, wo sie der Gezeitenströmung und dem Wellenschlag ausgesetzt sind. Es wäre daher zu erwarten, daß beide Arten auch bei Helgoland vorkommen, wo jedoch die Population als einheitlich befunden wurde, von morphologischen Unterschieden ihrer Individuen abgesehen.

Koeman \& van den Hoek $(1981,1982 a, b, 1984)$ räumen ein, daß die Taxonomie von 
Ulva und Enteromorpha schwierig ist, weil alle mikroskopischen und makroskopischen Merkmale in hohem Maße variabel sind. Die äußere Gestalt von U.pseudocurvata wird wie folgt beschrieben: Thallus mittel- bis hellgrün, oval, umgekehrt oval, schwach verkehrt eiförmig und gekrümmt, aber bis zu linear und gerade variierend, oft gelappt, zarthäutig und leicht schlüpfrig. Thallusende stumpf abgerundet, Basis keilförmig bis herzförmig mit einem kleinen zarten Stiel mit Haftscheibe.

Diese Beschreibung von U.pseudocurvata bezieht sich ganz offensichtlich im wesentlichen auf jüngere, durch ihre schlanke, oftmals gekrümmte Form auffallende Stadien. Die älteren unregelmäßigen und gelappten Thalli (Koeman \& van den Hoek 1981, Abb. 15, 16) müssen aber notwendigerweise dieses Stadium durchlaufen haben. Die Variabilität der Ulva-Thalli ist nur aus ihrer Entstehungsgeschichte zu verstehen. Dafür ist $U$.pseudocurvata ein besonders geeignetes Beispiel, wie auch schon eingangs dargestellt.

Koeman \& van den Hoek (1981) beschreiben den Thallus von U. lactuca als meist unregelmäßig rund oder unregelmäßig ausgebreitet, mit tief herzförmiger bis abgerundeter Basis; kleinere Thalli können auch mitunter linear sein. Aber können die unregelmäßigen lactuca-Thalli anders als die von $U$.pseudocurvata entstehen? An einer als einheitlich erkannten Population von U. lactuca ließe sich diese Frage klären.

Zum Unterschied von dem zarthäutigen pseudocurvata-Thallus wird U.lactuca als verhältnismäßig steif bezeichnet, so daß der Thallus nach dem Falten zurückspringt. Als absolutes Unterscheidungsmerkmal wird die Struktur der Basis angegeben. Aufsichtsbilder auf die Basalregion zeigen bei etwa $85 f$ acher Vergrößerung deutlich dunkel gefärbte Rhizoide bei U.lactuca, während normale und rhizoidale Zellen bei $U$.pseudocurvata einander ähnlich sind (Koeman \& van den Hoek 1981, Abb. 31 bzw. 77). In unserer Helgoländer Population konnten wir keine Exemplare auslesen, die aufgrund eines verhältnismäBig steifen Thallus als $U$. lactuca angesprochen werden könnten. Überdies glichen die mikroskopisch geprüften Exemplare der Abbildung von U. pseudocurvata.

Die Typifizierung der Gattung Ulva Linnaeus ist durch Papenfuss (1960) gesichert, doch können weder das einzige Typusexemplar von U. lactuca (Fig. 10) noch die Querschnittsbilder durch den Thallus (Fig. 1, 2) die Art kennzeichnen. So war U. lactuca lange Zeit der Repräsentant der Gattung, freilich mehr nach subjektivem Ermessen der Autoren als auf einer taxonomisch gesicherten Basis, sofern nicht durch morphologische, ökologische oder entwicklungsgeschichtliche Merkmale die Identität mit anderen Arten ausgeschlossen werden konnte.

\section{Ulva tenera sp. nov. (Abb.3-5)}

Diagnosis: Ulva tenera Kornmann, species nova inter Ulvaceas. Thallus tenerus, e laminis viridibus et linearibus consistens, in regione basali regulariter cuneiformis, sed numquam cordiformis, et saepe stipite ad $1 \mathrm{~mm}$ longo suppositus, ad substratum per haptera rhizoidalia affixus. Apex obtusus vel irregulariter emarginatus post fecunditationem. Longitudo thalli usque ad $6 \mathrm{~cm}$, latitudo usque ad $2,5 \mathrm{~cm}$, crassitudo ca. $32 \mu \mathrm{m}$. Cellulae regionis medianae et apicalis ex aspectum superficialem aequalis diametris et 8-10 $\mu \mathrm{m}$ latae. Chloroplastus una pyrenoide. Pars fecunda tantum in regione apicalis et de parte vegetativa inferiore distincte delimitata, incrementum thalli ex hac ortum usque ad proximam fecunditationem. Zoosporae conspicue elongatae et biflagel- 


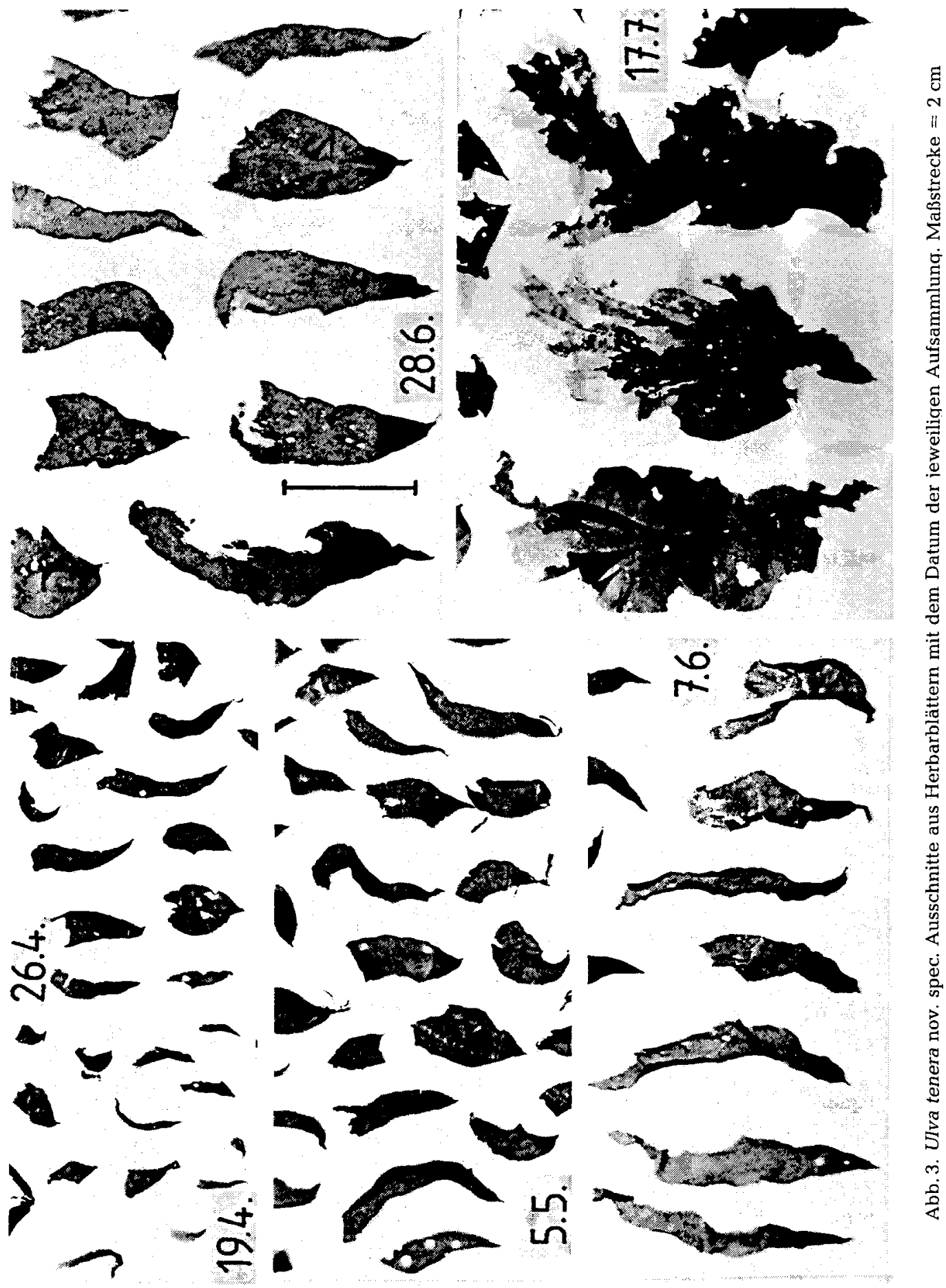




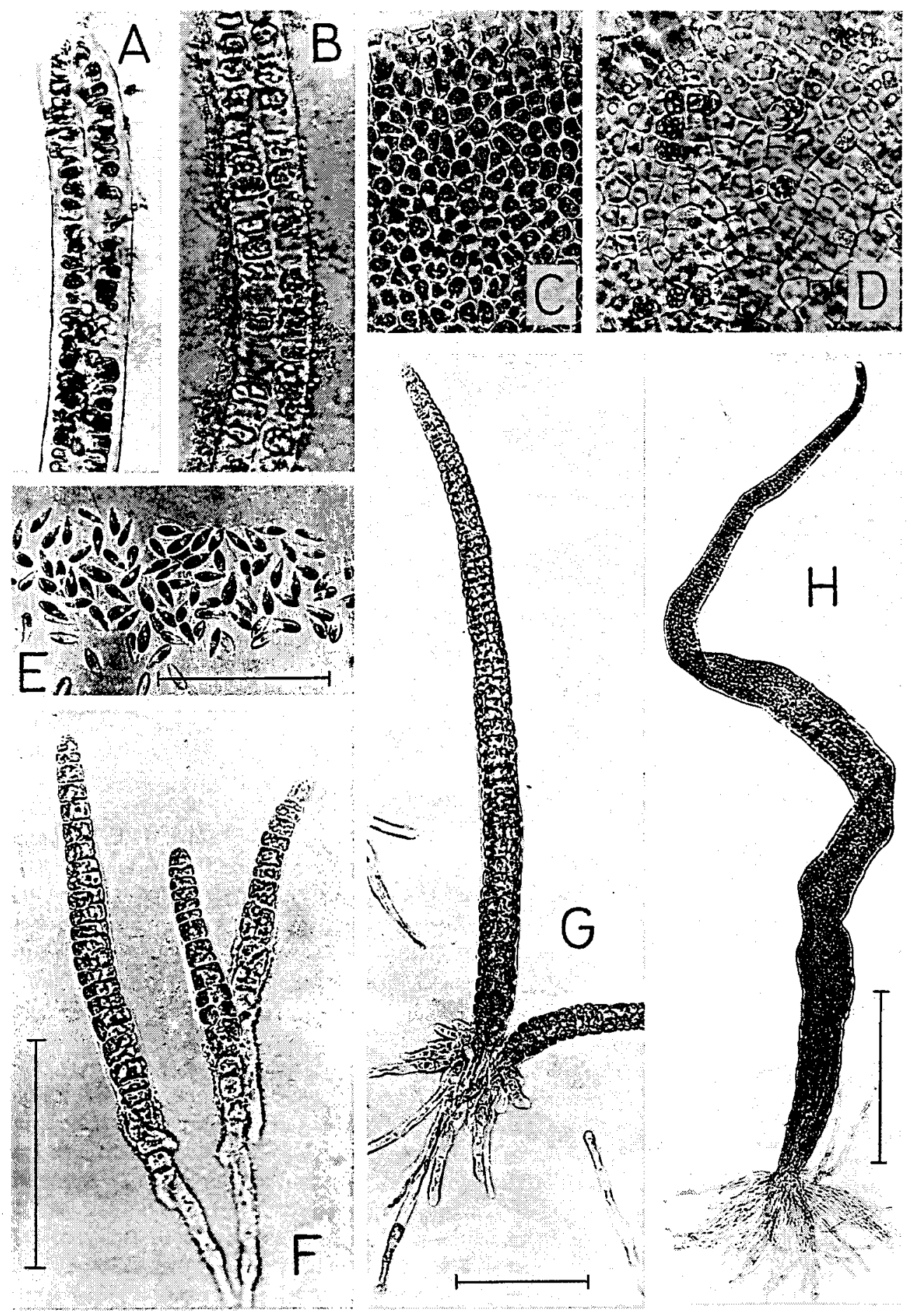




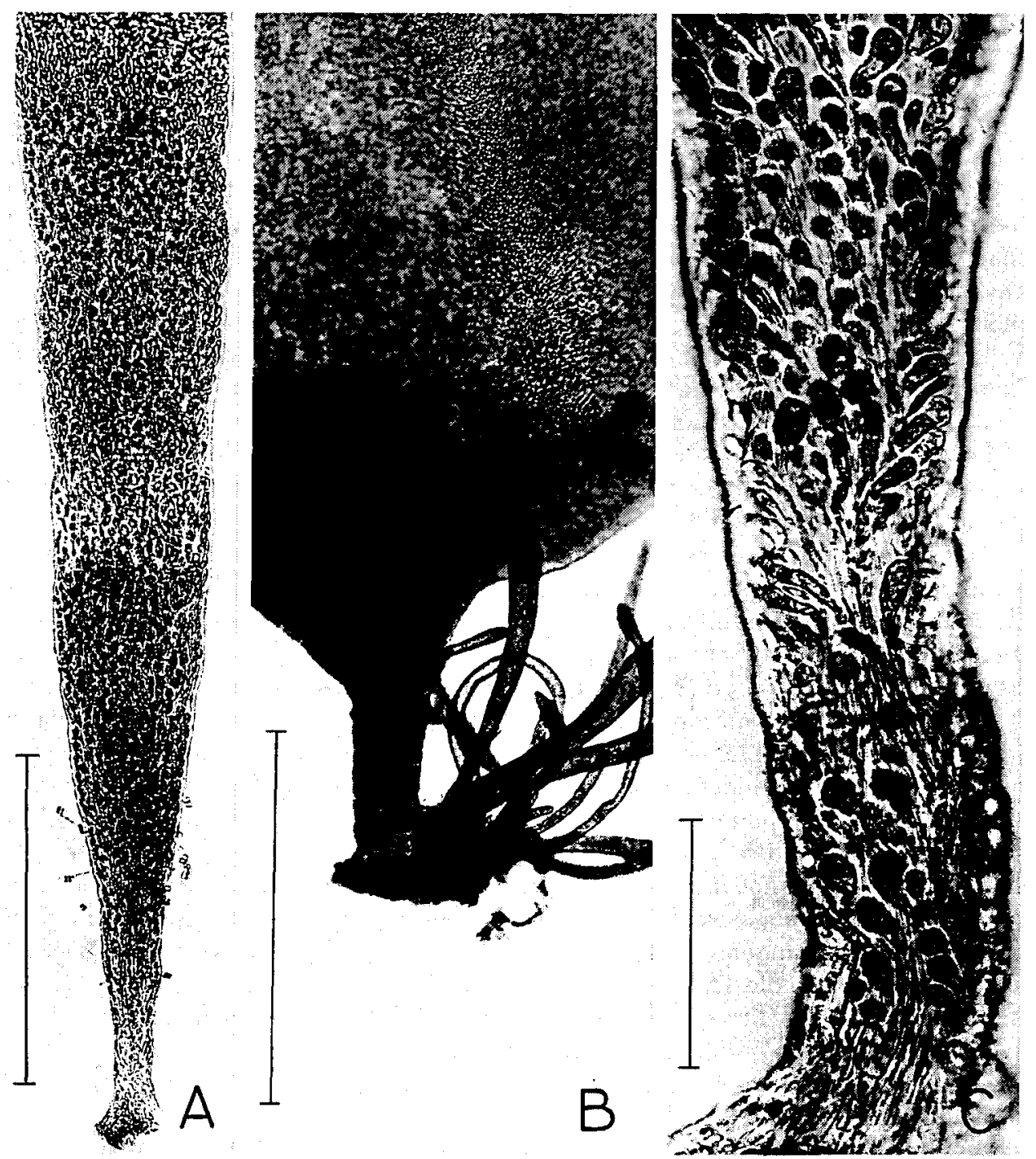

Abb.5. Ulva tenera nov. spec. A: Basis einer $6 \mathrm{~mm}$ langen Pflanze. Spundwand Oststrand 19. 4. 1978. B, C: Basis einer alten Pflanze, zusammen mit Blidingia minima. Von Beton der zerstörten Westmole (11. 8. 1980). Maßstrecken: $A=0,5 \mathrm{~mm}$; $=1 \mathrm{~mm}$; $C=100 \mu \mathrm{m}$

Abb. 4. Ulva tenera nov. spec. A, B: Querschnitt durch den vegetativen und fertilen Thallus. C, D: Thallusaufsicht vegetativ und fertil. E: Zoosporen. F-H: Aus 9, 12 und 19 Tage alten Kulturen. Maßstrecken: $A-D, F=100 \mu \mathrm{m} ; E=50 \mu \mathrm{m} ; \mathrm{G}=100 \mu \mathrm{m} ; \mathrm{H}=0,5 \mathrm{~mm}$ 
latae, 9-10 $\mu \mathrm{m}$ longae, usque ad $2 \mu \mathrm{m}$ latae, lucem fugentes. Solum propagatio asexualis observata. Habitat in zona eulitorali superiore intermixta cum Blidingia minima.

Diagnose: Für Ulva-Arten ungewöhnlicher Standort: oberes Eulitoral zusammen mit Blidingia minima. Vermehrung durch zweigeißelige Zoosporen. Thallus zart, keilförmig unmittelbar über einem bis $1 \mathrm{~mm}$ langen Stielchen sich verbreiternd, bis $6 \mathrm{~cm}$ lang, bis $2,5 \mathrm{~cm}$ breit, etwa $32 \mu \mathrm{m}$ dick. Zellen in der Aufsicht isodiametrisch 8-10 $\mu \mathrm{m}$ groß mit einem Pyrenoid. Das Zellumen ist etwa $12 \mu \mathrm{m}$ hoch. Der apikale Teil wird fertil und ist scharf von dem vegetativen Teil abgegrenzt. Dieser setzt das Wachstum bis zur neuen Schwärmerbildung fort. Die zweigeißeligen Zoosporen sind negativ phototaktisch, auffallend schlank, 9-10 $\mu \mathrm{m}$ lang und bis zu $2 \mu \mathrm{m}$ breit. Da sich Größe und Form der Alge während ihrer Vegetationszeit ständig verändern, vermitteln alle Stadien der Abbildung 3 in ihrer Gesamtheit nur eine Vorstellung des "Typus".

Zwei Merkmale unterscheiden diese zarte Ulva von den meisten übrigen Arten. Sie wächst im oberen Eulitoral in Gemeinschaft mit Blidingia minima, einem für Ulva ungewöhnlichen Standort. Sie vermehrt sich durch zweigeißelige Zoosporen, was ebenfalls nur bei wenigen Arten der Gattung der Fall ist.

Die Alge wurde von April bis August 1978 laufend an der ehemaligen eisernen Spundwand vor der Kurpromenade gesammelt, 1982 auch schon im Februar. Die Spundwand wurde inzwischen durch Betonplatten erneuert. Durch die Exposition nach Norden ist ihr Bewuchs auch im Sommer vor allzu starker Austrocknung geschützt. Ausschnitte aus unseren Aufsammlungen sind in natürlicher Größe auf Abbildung 3 dargestellt. Am 19. April waren viele Pflänzchen noch schmal lanzettlich, etwa $1 \mathrm{~cm}$ lang und $1 \mathrm{~mm}$ breit, oft waren mehrere zu kleinen Büscheln vereinigt. Einige Thalli waren auch bis etwa $4 \mathrm{~mm}$ breit, doch war deren apikales Ende nicht mehr abgerundet, sondern nach vorausgegangener Fertilisierung unregelmäßig abgestumpft. Die Basis verschmälert sich in ein dünnes Stielchen (Abb. 5 A). Eine Kratzprobe vom 26. 4. 1978 enthielt schon wesentlich größere, bis zu $2 \mathrm{~cm}$ lange und 5-6 $\mathrm{mm}$ breite Pflänzchen, einige waren auch rundlich auf einem sehr deutlich abgesetzten Stielchen. Den meisten fehlte die abgerundete Spitzenzone nach vorangegangener Fertilisierung. Aus dem stets vegetativ bleibenden Basisabschnitt erneuern sich die Thalli; sie nahmen im Mai und Juni stark an Breite und Länge zu. Die zunehmende Erwärmung im Juni und Juli dürfte das Wachstum besonders begünstigt haben, die größten Pflanzen erreichten $6 \mathrm{~cm}$ Länge. Sie waren etwas kraus geworden und nach dem Trocknen faltig. In allen Stadien ihrer Entwicklung bleibt die Grundform der Alge keilförmig, die Basis wird niemals herzförmig, sondern verbreitert sich unmittelbar über einem ausgeprägtem, oft $1 \mathrm{~mm}$ langen Stielchen (Abb. $5 \mathrm{~B}, \mathrm{C}$ ).

Der Thallus dieser Ulva ist etwa $32 \mu \mathrm{m}$ dick (Abb. 4 A, B). Dementsprechend zeigt die Aufsicht auf den Thallus ein Netz aus etwa isodiametrischen 8-10 $\mu \mathrm{m}$ großen Zellen. Sie enthalten ein Pyrenoid, ihr Lumen ist etwa $12 \mu \mathrm{m}$ hoch. Querschnitte durch den fertilen Thallus zeigen flaschenförmige Sporangien, aus denen die Zoosporen durch einen Porus entleert werden; die Öffnungen sind in dem leeren Zellnetz besonders klar sichtbar (Abb. 4 D). Die Schwärmerbildung erfolgt in der apikalen Zone und wird oft scharf von dem vegetativ gebliebenen Thallusabschnitt abgegrenzt. Dieser setzt das Wachstum bis zur erneuten Schwärmerbildung fort.

Die zweigeißeligen, negativ phototaktischen Zoosporen sind auffallend schlank, 9-10 $\mu \mathrm{m}$ lang und bis zu $2 \mu \mathrm{m}$ breit. Thre Entwicklung in Kultur während 19 Tagen ist in Abbildung 4 F-H dargestellt. Die schmalen $6 \mathrm{~cm}$ langen Thalli waren nach 6 Wochen fertil. 
Größe und Form dieser Alge verändern sich ständig während ihrer Vegetationszeit, und somit vermitteln nur alle Stadien der Abbildung 3 in ihrer Gesamtheit eine Vorstellung des "Typus". Sicherlich ist die laufende Beobachtung solcher Algen an ihrem Standort während einer längeren Vegetationszeit eine nicht immer leicht erfüllbare, indessen aber doch notwendige Grundlage für ihre Kennzeichnung. Aus ihren etwas dickeren zweigeißeligen Schwärmern entstehen Thalli, die ganz denen unserer Helgoländer Art gleichen.

Bliding weist auf die nahe Verwandtschaft dieser Art mit Ulva linearis Dangeard hin, * deren Thallus jedoch nur 25-30 $\mu \mathrm{m}$ dick ist und entsprechend kleinere Zellen hat. Ardré (1970) fand diese von Marokko beschriebene Art im April 1963 an der portugiesischen Küste. Sie wuchs in der oberen litoralen Zone an beschatteten Felsen, mitunter zusammen mit Blidingia minima. Die von Ardré nur einmal gefundenen bandförmigen Thalli waren bis zu $2 \mathrm{~cm}$ lang und 3-6 mm breit. Die abgebildeten Querschnitte sind 28-30 $\mu \mathrm{m}$ dick. Obwohl diese Merkmale gut für junge Exemplare der zarten Ulva von Helgoland zutreffen, erscheint uns die Identität mit $U$. linearis nicht genügend gesichert. Die Ergebnisse von Kulturversuchen (Gayral, 1959-1960) mit $U$. linearis sind zu eigenartig, um im Zusammenhang mit unseren Befunden diskutiert zu werden.

Die Durchsicht unseres Algenherbariums von List/Sylt erbrachte eine Überraschung: in dem reichhaltigen Material nicht näher bestimmter Exsikkate von Ulva fiel eine zarte Ulva durch ihren Habitus als Besonderheit auf. Sie wuchs an den Pfählen der ehemaligen Landungsbrücke auf dem Ellenbogen während des ganzen Jahres und ist durch zahlreiche Aufsammlungen von 1957-1959 belegt. Am 23. 9.1957 wurden 16 fertile Pflanzen untersucht. Alle Pflanzen entleerten zweigeißelige Schwärmer, die nicht miteinander kopulierten. Zeichnungen vom 13. 11. 1957 zeigen den $32 \mu \mathrm{m}$ dicken Thallus, dessen kleine Zellen ein Pyrenoid enthalten.

Wahrscheinlich ist die lange Zeit übersehene zarte Ulva in der Nordsee - zum mindesten in der Deutschen Bucht - heimisch. Im März 1992 wurde sie in Helgoland an demselben Standort wie 1978 wiedergefunden, nunmehr in den Rillen zwischen aneinandergefügten Betonplatten.

Die Identifizierung dieser zarten Ulva gibt Rätsel auf. Wie konnte an den so gründlich untersuchten Atlantikküsten der kaltgemäßigten Florenregion an zwei etwa $100 \mathrm{~km}$ voneinander entfernten Standorten eine so charakteristische UIva-Art verborgen bleiben? Kann man sie als neue Art ansehen?

Für einen Vergleich kommen zwei Arten aus wärmeren Meeren in Betracht. Ausschließlich ungeschlechtliche Vermehrung, eine gleichartige ontogenetische Entwicklung und den deutlich in ein Stielchen sich verschmälernden Thallus teilt sie mit Ulva neapolitana Bliding $(1960,1968)$. Deren Habitus erinnert aber an Enteromorpha linza, auch ist der Thallus wesentlich größer und dicker (ca. $50 \mu \mathrm{m})$, wie auch die Schwärmer dicker sind $(8,4 \times 4,2 \mu \mathrm{m})$.

Von der marokkanischen Atlantikküste wurde, wie oben erwähnt, eine nur 25-30 $\mu \mathrm{m}$ dicke Art mit zweigeißeligen Zoosporen beschrieben, Ulva linearis Dangeard (1957). Ihr bandförmiger Thallus ist 5-6 cm lang und 5-6 $\mathrm{mm}$ breit. Ardré (1970) gibt

\footnotetext{
:Anmerkung der Herausgeber: Bliding (1968) vergleicht in seiner Arbeit die Arten UIva neapolitana Bliding und Ulva linearis Dangeard, und weist auf die nahe Verwandtschaft dieser beiden Arten hin.
} 
einen einmaligen Fund an der portugiesischen Küste an. Die $2 \mathrm{~cm}$ langen und 3-6 mm breiten Thalli entsprechen zwar der Originalbeschreibung, in der aber keine Angaben über eine etwaige altersmäßig bedingte Variabilität enthalten sind.

Natürlich kann man von floristischen Felduntersuchungen im allgemeinen keine Einblicke in die Lebensgeschichte einer Alge erwarten, wie sie bei stationärer Beobachtung möglich sind. Auf dieser Grundlage halten wir die Beschreibung einer neuen Art, Ulva tenera, für berechtigt.

\section{? Ulvaria oxysperma}

Diese an den europäischen Küsten verbreitete Alge fehlt auch nicht bei Helgoland. Allerdings tritt sie hier nur wenig in Erscheinung. Ausgewachsene Exemplare findet man selten, dagegen traten ihre unverkennbaren Jugendstadien häufig in Rohkulturen auf, zum Beispiel mit Kratzmaterial von Spundwänden, auf ausgelegten Versuchsplatten, einmal auch in Rohkulturen mit Thallus-Stückchen von Porphyra insolita.

Die von uns untersuchten Proben wurden am 11. und 13. Mai 1977 auf Trümmersteinen des ehemaligen U-Boot-Bunkers gesammelt, wo sie im oberen Eulitoral zusammen mit Blidingia marginata wuchsen. Es waren bis etwa $6 \mathrm{~cm}$ große rosettenartige Thalli (Abb.6 A). Die für einen Kulturversuch ausgewählte Pflanze hatte am Rand reife Sporangien, nach innen folgten alle Übergangsstadien bis zu vegetativen Zellen. Zellen in der Thallusmitte sind rundlich und in der Aufsicht 10-15 $\mu \mathrm{m}$ groß (Abb. 6B). Am Thallusrand sind sie deutlich größer und lösen sich aus dem Verband, bevor sie in dem verquellenden Saum fertil werden $(6 \mathrm{C}, \mathrm{D})$. Die zweigeißeligen, negativ phototaktischen Zoosporen waren ca. 9,5 × 1,5 $\mu \mathrm{m}$ groß, also schlanker als von Bliding (1968) angegeben (Abb. $6 \mathrm{E}$ ). Ihre zunächst fädigen Keimlinge wurden nach 13 Tagen röhrenförmig und entwickelten sich zu einschichtigen Schläuchen, die sich am Scheitel öffnen (6F, G). Die horizontal wachsenden Randlappen vergrößern sich zu dem einschichtigen Thallus, wie es die Abbildungen $6 \mathrm{H}$ und I der in Rohkulturen entstandenen kleinen Thalli zeigen. In den Kulturen entstandene große Pflanzen fruktifizierten wiederum mit zweigeißeligen Zoosporen, wie auch schon aus den Untersuchungen früherer Autoren bekannt ist.

Wegen ihrer gleichartigen ontogenetischen Entwicklung mit der diözischen Ulvaria obscura hat Bliding (1968) die früher als Monostroma oxysperma bezeichnete Art dieser Gattung zugeführt. Gegen diese Kombination wurden neuerdings gewichtige Bedenken geltend gemacht, die aber im Rahmen unserer floristisch ausgerichteten Studie nicht weiter diskutiert werden sollen. Es sei hier nur auf eine Studie von Golden \& Garbary (1984) hingewiesen, in der die Sporenentleerung monostromatischer Arten der pazifischen Nordküste untersucht wurde. Die Autoren führen mehrere von Monostroma abgetrennte Gattungen ihr wieder zu. Die Problematik wird ebenso aus einer Veröffentlichung von O'Kelly et al. (1984) ersichtlich: "The fine structure of motile cells in the genera Ulvaria and Monostroma, with special reference to the taxonomic position of Monostroma oxyspermum (Ulvophyceae, Chlorophyta)."

Abb.6. Ulvaria oxysperma. A: Rosettenartiger Thallus. B: Vegetative Zellen, Thallusmitte. C, D: Deutlich größere fertile Zellen am Thallusrand, die sich aus dem verquellenden Saum lösen. E: Zweigeißelige Zoosporen, F: Keimlinge, die sich (G) zu röhrenförmigen Schläuchen entwickeln und sich am Scheitel öfnen. H, I: Die horizontal wachsenden Randlappen vergrößern sich zu einem einschichtigen Thallus. Maßstrecken: $A=6 \mathrm{~cm} ; \mathrm{B}, \mathrm{C}, \mathrm{D}=50 \mu \mathrm{m} ; \mathrm{E}=50 \mu \mathrm{m} ; \mathrm{F}=100 \mu \mathrm{m}$; $\mathrm{G}, \mathrm{H}=0,5 \mathrm{~mm} ; \mathrm{I}=1 \mathrm{~mm}$ 

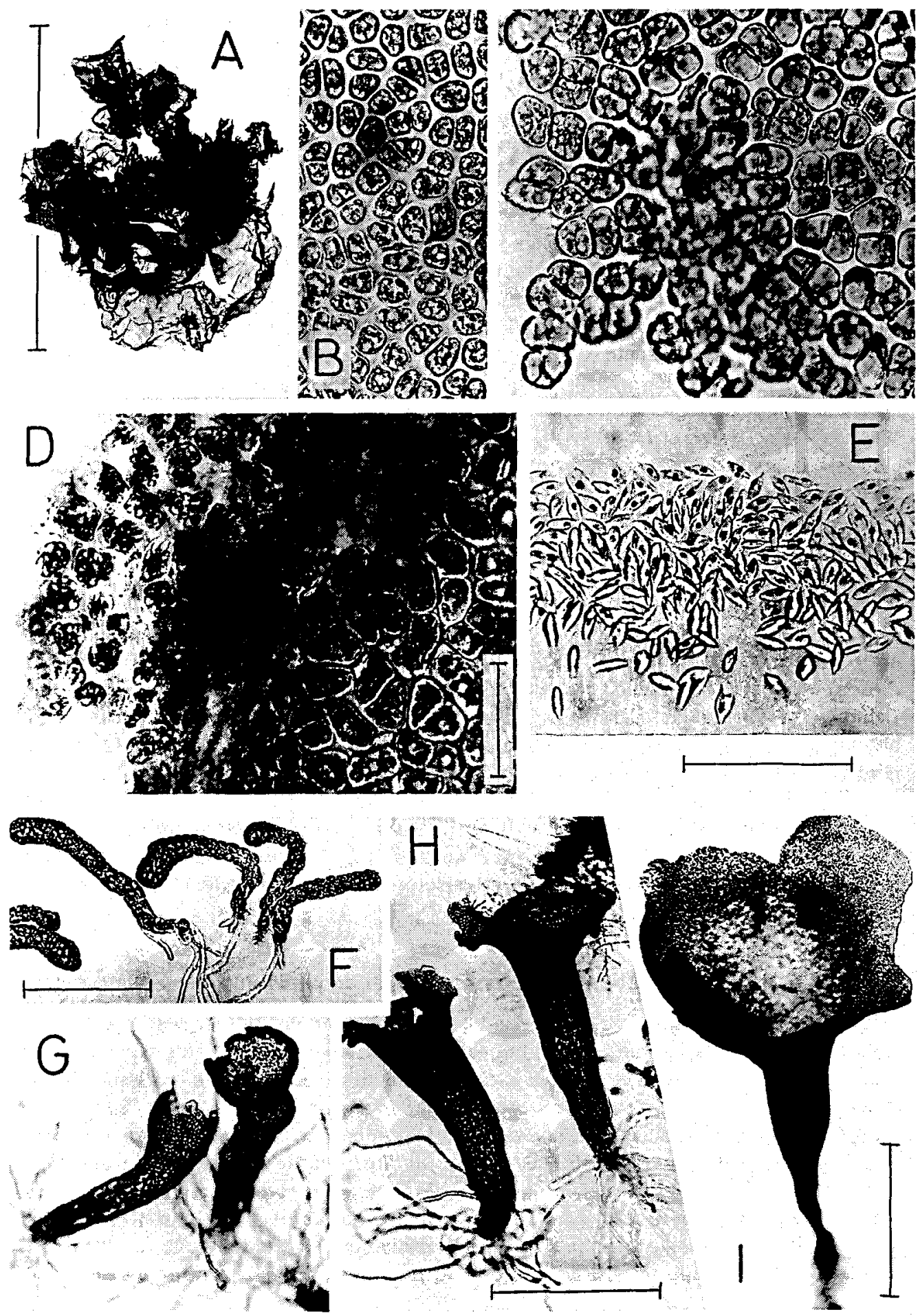
Ohne eigene Stellungnałme haben wir vor den gewählten Gattungsnamen ein Fragezeichen gesetzt.

Urospora curvata (Printz) nov. comb.

Basionym: Uronema curvata Printz (1926, p. 233, Taf. VIII, Fig. 105-114)

Printz (1926) führte der mit mehreren Arten im Süßwasser vertretenen Gattung Uronema Lagerheim eine marine Art zu: U.curvata. Die aus dem Trondhjemsfjord beschriebene Alge ist nur sehr selten wiedergefunden worden. Waern (1958, p. 335) erwähnt ihr Vorkommen am Nordkap und an der schwedischen Westküste. South (1984) gibt sie für die Ostküste Kanadas an. Ihr Vorkommen in dem wärmeren Teil der kaltgemäßigten Region bei Roscoff (Feldmann, 1954) ist ebenso unsicher, wie das Vorkommen bei Irland (South \& Tittley, 1986) nicht belegt ist.

Uronema curvata ist uns nur einmal auf dem Schalenboden einer Rohkultur mit Material aus dem Sublitoral vom 31.Januar 1984 begegnet; in ihr wurde sie erst zwei Monate später bemerkt (Abb. 7 A). Reinkulturen konnten nicht erhalten werden, doch sind die Beobachtungen an den Rohkulturen eine wertvolle Ergänzung der Beschreibung von Printz.

Der Habitus unserer Alge entspricht gut der Originalbeschreibung, jedoch ist sie in allen Abmessungen wesentlich größer. Die mehr als $500 \mu \mathrm{m}$ langen gekrümmten Fäden sind an den Querwänden deutlich eingeschnürt, ausgewachsene Zellen sind durchschnittlich $50 \mu \mathrm{m}$ lang und bis zu $20 \mu \mathrm{m}$ breit, können aber auch $150 \mu \mathrm{m}$ erreichen (Abb. $7 \mathrm{~F})$. In den fertilen Abschnitten sind sie leicht keulenförmig, das apikale Ende ist am breitesten. Dort liegt auch die Austrittsöffnung für die Schwärmer ( $7 \mathrm{G}$ ). Sie ist in dieser Figur noch durch eine vorgewölbte hyaline Blase verschlossen. An den entleerten Zellen wird die äußerst zarte Membran erkennbar. Freie Schwärmer konnten nicht beobachtet werden, in einem reifen Sporangium sind sie langgestreckt mit zugespitztem Hinterende (7 D, G). Die Keimlinge zeigen deutlich einen grob netzförmigen Chromatophor $(7 \mathrm{~A}, \mathrm{~B})$, der in den älteren vegetativen Zellen sehr dicht wird.

Aufgrund der hier vorliegenden Befunde kann Uronema curvata weder bei den Chaetophoraceae (South \& Tittley, 1986) noch bei den Ulotrichaceae (South, 1984) verbleiben. Die zugespitzten Schwärmer weisen ihr den Platz bei den Codiolaceae zu; wir stellen sie zur Gattung Urospora.

\section{Pseudendoclonium dynamenae Nielsen}

Grüne Endophyten in Bryozoen und Hydroiden wurden bis vor wenigen Jahren unterschiedlos als Epicladia flustrae angesehen. Eine systematische Untersuchung von Nielsen (1984) ergab jedoch, daß es sich hier um drei verschiedene, wirtsspezifische Arten handelt. Nur der in den Bryozoen Flustra foliacea und Securiflustra securifrons lebende Endophyt ist mit Epicladia flustrae Reinke identisch. Eine von Batters beschriebene Varietät auf Alcyonidium, E. flustrae var. phillipsii, wurde zum Rang einer selbständigen Art erhoben. Schließlich wurde der in der Theca des Hydroidpolypen Dynamena pumila wachsende Endophyt der Gattung Pseudendoclonium zugeführt. Der einzige Wirt von P. dynamenae ist der im Artnamen bezeichnete Hydroidpolyp.

Dynamena pumila wächst bei Helgoland häufig auf Fucus serratus. In den etwa 

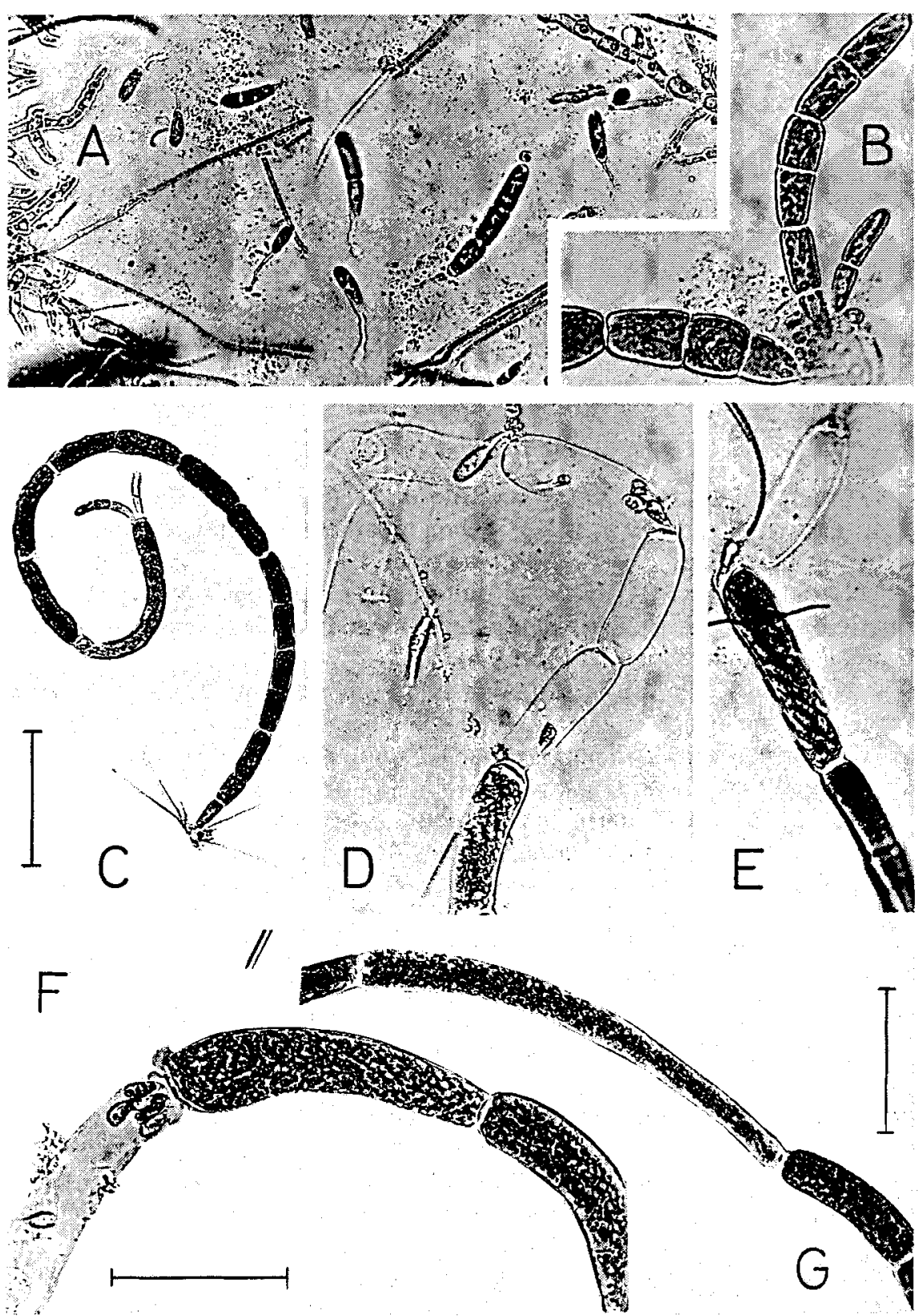

Abb. 7. Urospora curvata nov. comb. A: Aufsicht auf den Boden einer Rohkultur mit Keimlingen und wenigzelligen Fädchen. B, C: Vegetative Pflanzen; der Faden bei $C$ trägt apikal zwei Keimlinge. D-G: Fadenstücke mit Sporangien oder leeren Zellen. Maßstrecken: A, D-F =50 $\mu \mathrm{m}$; B, G = 50 $\mu \mathrm{m}$;

$$
\mathrm{C}=100 \mu \mathrm{m}
$$


$25 \mathrm{~mm}$ hohen, meist unverzweigten Stöckchen ist der Endophyt ziemlich regelmäßig anzutreffen (Abb. $8 \mathrm{~A}$ ). Das Zentrum einer Pflanze bildet eine dichte pseudoparenchymatische Schicht aus nahezu isodiametrischen 2-3 $\mu \mathrm{m}$ großen Zellen (Abb. $8 \mathrm{C}$ ). Die einzeln in der Theka sich ausbreitenden verzweigten Fäden haben zylindrische, etwa 4,5 $\mu \mathrm{m}$ breite Zellen, die vor ihrer Teilung doppelt so lang sein können (Abb. 8B). Der wandständige Chromatophor trägt einen Pyrenoid.

Pflanzen mit leeren Sporangien in der dichten Mitte wurden im Juli 1978 gesammelt (Abb.8C). Die Schwärmer entwickeln sich in freier Kultur sehr gut. Der Inhalt der Zoospore tritt in den jungen Keimfaden über, die leere Zoosporenmembran ist deutlich zu erkennen (Abb. 8 D, E). Vier Wochen alte kultivierte Pflanzen sind dem Naturmaterial recht ähnlich (Abb. 8 F).

\section{Phaeophila tenuis (Kylin) Nielsen Syn. Entocladia tenuis Kylin}

Zur Prüfung auf grüne Endophyten wurde am 24.7. 1978 eine Miesmuschelschale in eine Petrischale mit Nährlösung gelegt. Schon innerhalb einer Stunde konnten zahlreiche viergeißelige Schwärmer vom Lichtrand isoliert werden. Eine vier Tage alte Kultur enthielt fast nur einheitliche Keimlinge mit einem eigenartigen Merkmal: bis zu der Austrittsstelle des jungen Fadens war die Sporenwandung als braune Kappe mit einem deutlichen Kragenrand abgesetzt (Abb.9A).

Mehrere Jahre lang wurde die Alge in unseren Protokollen als "Braunkappe" bezeichnet, bis schließlich eine Abbildung bei Nielsen (1980) zu ihrer Identifizierung führte. Eine rasterelektronenmikroskopische Aufnahme zeigt einen Keimling von Phaeophila tenuis mit einem kragenartigen Ring an der Stelle, wo der junge Faden die Zoospore verläßt. Eine Braunfärbung der Zoosporenwand wird jedoch nicht erwähnt.

Die Ende Juli angelegten Kulturen waren Anfang Dezember fertil (Abb.9E, F), Mit ihren viergeißeligen Schwärmern wurden die Kulturversuche wiederholt. Drei Tage alte Keimlinge zeigten die braunen Wandkappen (Abb.9C). Auf Kalkschalen gekeimte Zoosporen waren schon mit kurzen Fädchen in das Substrat eingedrungen (Abb.9D). Die leere Zoosporenwand auf der Oberfläche des Substrats war eine durchsichtige Blase ohne erkennbare Braunfärbung. Die Fäden wuchsen in den Muschelschalen erstaunlich schnell, im Alter von 5 Tagen waren die gedrungenen Fäden nicht viel kleiner als die auf dem Schalenboden.

Vergleichende Kulturen mit einem 1958 in List/Sylt isolierten Stamm von Entocladia tenuis stimmten mit den Helgoländer Beobachtungen überein. Schon am zweiten Tage nach der Keimung läßt die Zoosporenwand eine Braunfärbung erkennen, die an den folgenden Tagen deutlicher wird. Die Schwärmer und die fünf Tage alten Keimungsstadien glichen ganz denen von Helgoland (Abb. 9 G-K).

Bei Entocladia tenuis ist die Braunfärbung nicht auf die Wandkappen der Keimlinge beschränkt. Auch die Sporangienwandung unseres Helgoländer Stammes ist in ihrem oberen Teil deutlich bräunlich gefärbt, besonders bei leeren Sporangien (Abb.9F).

Abb. 8. Pseudendoclonium dynamenae. A: Hydroid mit Endophyt. B, C: Periphere und zentrale, fertile Partie des Endophyten. D, E: Keimlinge 2 bzw. 7 Tage alt. F: 4 Wochen alte Pflanze aus einer Kultur. Maßstrecken: $A=200 \mu \mathrm{m} ; \mathrm{B}, \mathrm{C}=50 \mu \mathrm{m} ; \mathrm{D}-\mathrm{F}=500 \mu \mathrm{m}$ 

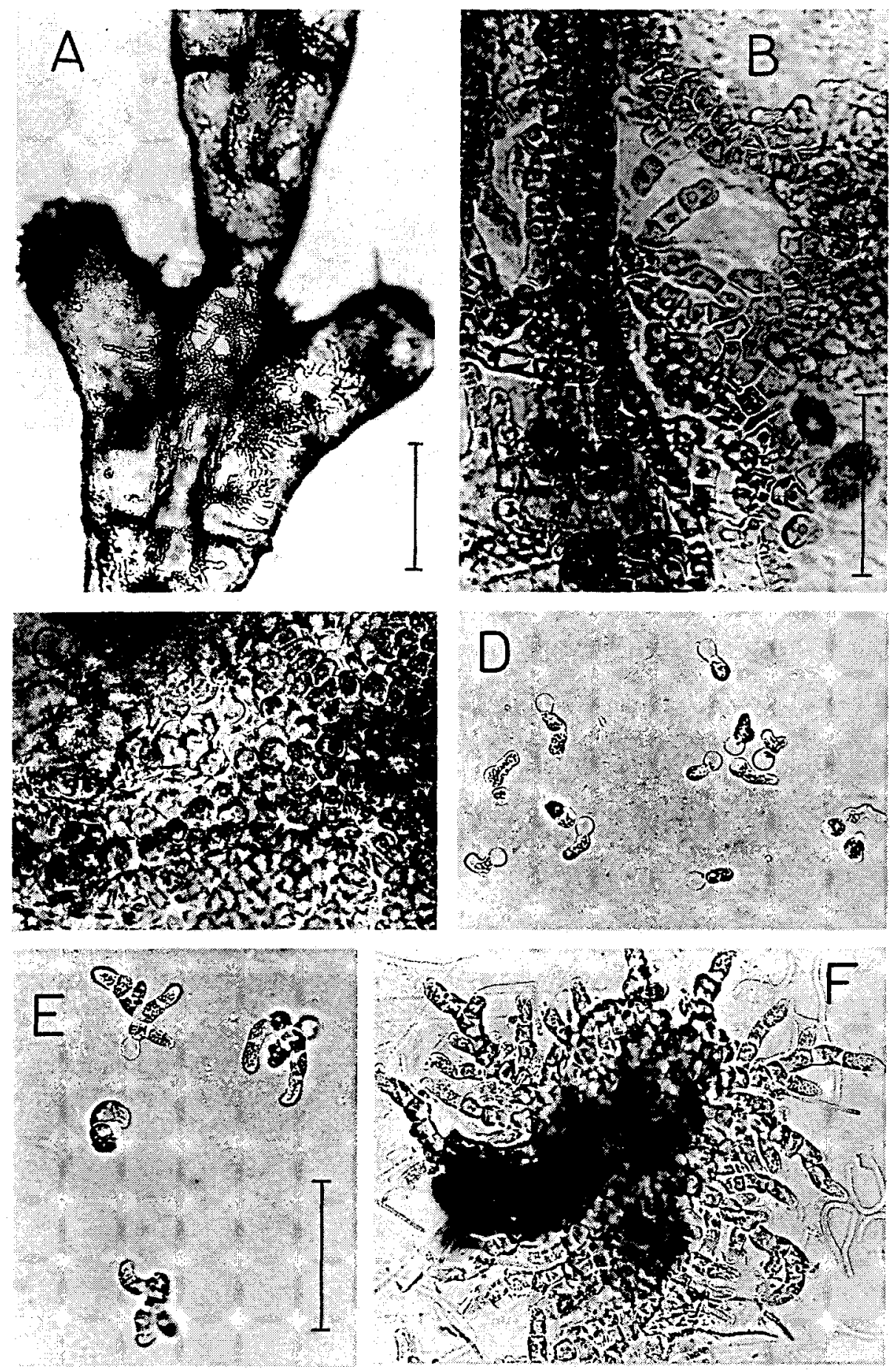

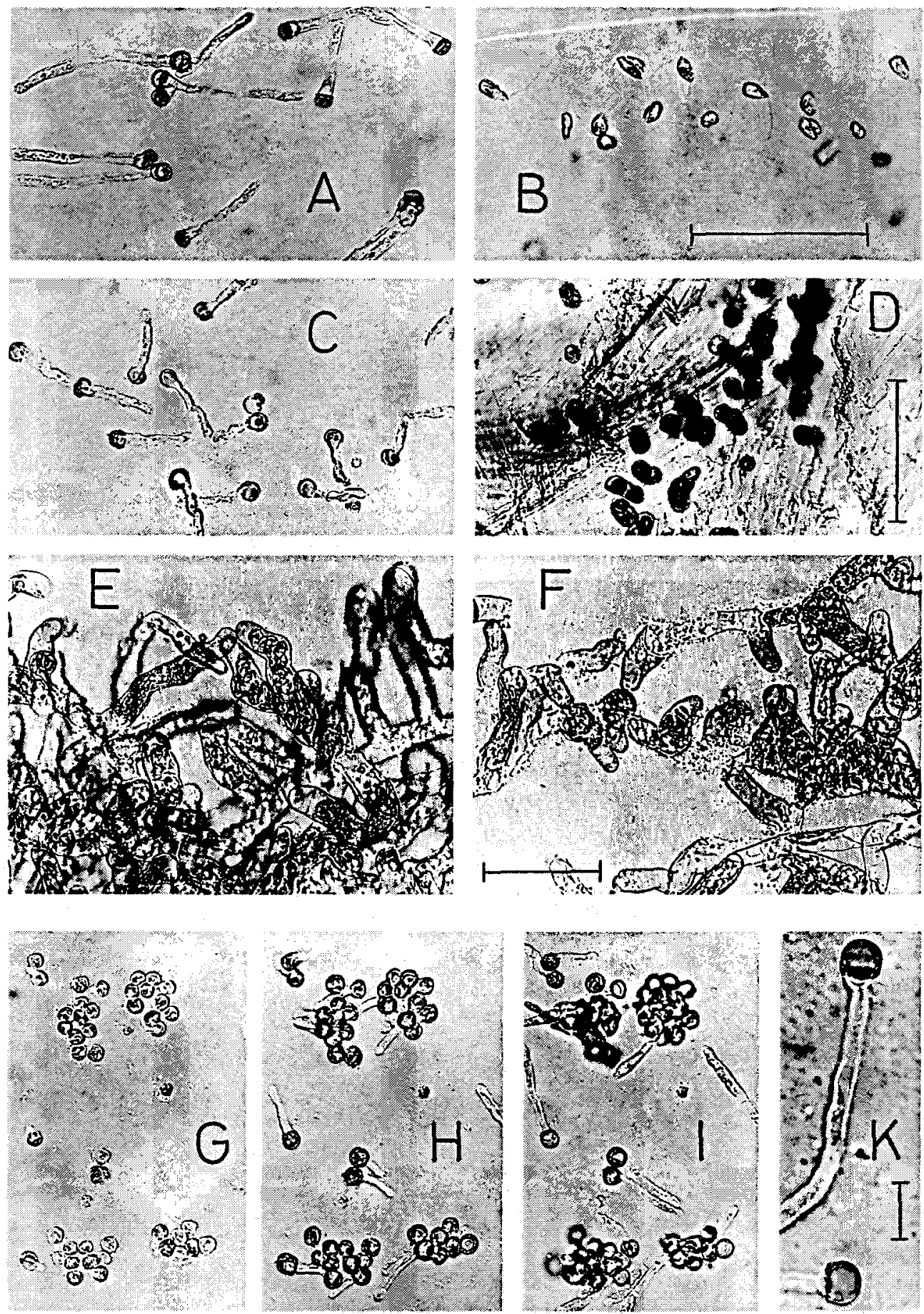
Ebenso können die Borsten bräunlich gefärbt sein; dies zeigen kolorierte, 1959 in List/ Sylt angefertigte Zeichnungen.

Über eine analoge Beobachtung berichteten kürzlich Correa et al. (1988) bei Acrochaete operculata. Das obere Drittel reifer Sporangien ist braun gefärbt, was besonders deutlich an der leeren Wandung in Erscheinung tritt. Dieses Merkmal kennzeichnet nur diese eine Art der Gattung.

Entocladia tenuis ist von Kylin (1935) und von Nielsen (1972) ausführlich beschrieben worden. Die Ausbildung von Borsten hängt offenbar sehr von äußeren Bedingungen der Kultur ab. An den beiden Stämmen von Helgoland waren sie äußerst selten, häufiger dagegen an einem früher in List/Sylt untersuchten Material.

Wegen des Vorkommens von Borsten schließt Nielsen (1972) die Alge aus der Gattung Entocladia aus und gliedert sie in die Gattung Phaeophila ein.

\section{BRAUNALGEN}

\section{Sphacelariaceae}

Eine erschöpfende taxonomische Bearbeitung der europäischen Sphacelariaceen verdanken wir Prud'homme van Reine (1982). Sie weist für Helgoland 9 SphacelariaArten nach und ist die Grundlage für die folgende Ergänzung beziehungsweise Korrektur unserer früheren Angaben.

Vier der häufig vorkommenden Arten sind in unserer Algenflora von 1977 dargestellt. Zu ihnen gesellt sich hier noch Sphacelaria nana. Die damals in unserer Abbildung 82 S. furcigera genannte Art muß jetzt S. rigidula Kützing heißen; dieser Name ist zwei Jahre älter und hat Priorität. S. furcigera ist nur eines von mehreren späteren Synonymen, wie auch die übrigen Arten unter mehreren synonymen Bezeichnungen in der Literatur zu finden sind.

\section{Sphacelaria nana Naegeli ex Kützing}

Sie bildet dunkelbraune bis olivgrüne weiche Rasen auf festem Untergrund. Aus der kriechenden Basis erheben sich die unverzweigten oder wenig verzweigten aufrechten Fäden, denen auch Rhizoide entspringen (Abb.10A). Unilokuläre und plurilokuläre Sporangien entstehen auf getrennten Pflanzen; sie sitzen den Segmenten einzeln auf. Die unilokulären Sporangien sind meist mehrzellig gestielt, kugelig bis schwach oval und 35-50 $\mu \mathrm{m}$ dick (Abb. 10 B). Die Größe der plurilokulären Sporangien schwankte in dem untersuchten Material erheblich. Auf meist kurzen Stielen waren sie im allgemeinen nur 50-60 $\mu \mathrm{m}$ lang (Abb. 10C), dagegen konnten sie auf mehrzelligen Stielen 100-180 um lang werden (Abb. 10 D).

Abb.9. Phaeophila tenuis. A: 4 Tage alte Kultur aus Schwärmern von Miesmuschelschale; Helgoland, 24. 7. 1978. B: viergeißelige Schwärmer aus Reinkultur. C, D: Drei Tage alte Keimlinge in freier Kultur und auf Kalkschale. E, F: Fertile Kultur aus Schwärmern vom 24. 7. 78, bei F mit deutlich dunklerer Sporangienwandung. G-K: Aus einer Reinkultur von List/Sylt: Keimlinge nach 1, 2, 3 und 5 Tagen. Maßstrecken: $A-D, G-J=50 \mu m_{;} E, F=50 \mu m_{i} K=10 \mu \mathrm{m}$ 


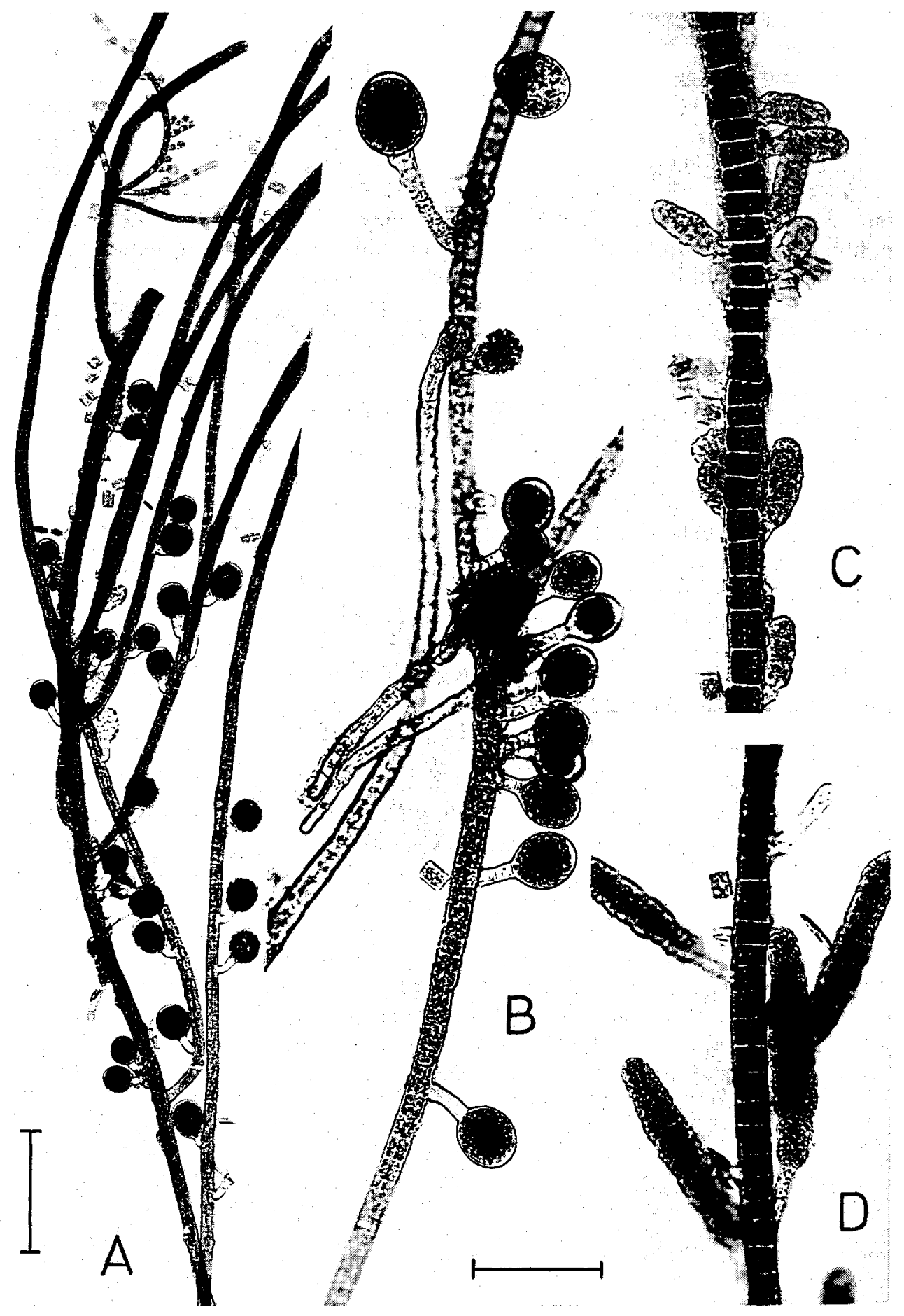




\section{Dictyota dichotoma (Huds.) Lamour.}

Ein reichliches Vorkornmen von Dictyota dichotoma ist uns vor drei Jahren im Bereich des Beckens vor der Westmole des Vorhafens bekannt geworden. Dieser Fund mußte um so mehr überraschen, als die Alge von dem Südwest-Felswatt im Laufe der letzten Jahrzehnte ganz verschwunden ist.

Mehr als 70 Jahre lang gehörte Dictyota zu den dort regelmäßig anzutreffenden Algen. Das Herbarium von Kuckuck enthält zahlreiche Exemplare vom Januar und Juli bis September, auch von anderen Standorten im Litoral. Nach Nienburgs Beobachtungen aus den Jahren 1921-1924 war die Alge in den flachen Gräben im unteren Teil der Abrasionsterrasse auch nach einer scharfen Frostperiode in der zweiten Januarhälfte 1922 als reine Sommerpflanze vertreten. In den dreiGiger Jahren kam Dictyota dort ebenfalls in großer Menge vor, und auch 1959 bis 1961, als wir unsere Beobachtungen in Helgoland wieder aufgenommen hatten, war sie in stattlichen Exemplaren anzutreffen. Unsere letzten Herbarpflanzen wurden im November 1961 auf dem Felswatt und im November 1962 an Betonsteinen vor der zerstörten Westmole gesammelt. Ein einzelner Tauchfund aus 0,5 m Tiefe auf einem Unterwasserblock vor der Westmole (Lüning, 1970) sowie ein Tauchfund durch Hans Reichenberger am 28.9. 1989 auf Trümmern der alten Westmole im Bereich des "Rosengartens" leitet zu dem eingangs erwähnten Vorkommen über. Das Becken besteht seit Mitte der fünfziger Jahre, nachdem die Westmole erneuert worden war. Es ist aber nicht bekannt, seit wann Dictyota an diesem nicht ohne weiteres zugänglichen Platz vorkommt.

Das am 28.9. 1989 gefundene Exemplar war eine $9 \mathrm{~cm}$ hohe männliche DictyotaPflanze; der Tauchgang am 28. Dezember 1989 - ebenfalls von Hans Reichenberger erbrachte nochmals 3 männliche Pflanzen. Diese waren schon deutlich überständig, einzelne Thallusenden waren beschädigt, die noch intakten begannen sich in schmale Lappen zu gabeln. Anfang September 1990 waren 2-3 m lange Exemplare von Sargassum muticum reichlich mit Dictyota-Keimlingen und bis zu 2,5 cm großen Thalli besetzt (Abb.11 A). Zugleich erbeuteten Taucher eine größere Menge erwachsener DictyotaPflanzen.

Die im Herbarium verwahrten Gametophyten und Sporophyten waren schon äußerlich erkennbar verschieden alt. Die jüngeren Pflanzen waren normal gestaltet, überständige Thalli an den Enden zu schmalen Lappen ausgewachsen (Abb.11B). Auf ihren dunkelbraun gefärbten basalen Teilen hatten sich Epizoen angesiedelt, bis $1 \mathrm{~mm}$ breite Spirorbis-Gehäuse und bis zu $2 \mathrm{~mm}$ breite Kolonien von Membranipora. Diese Tiere konnten nur aus einem Brutfall im Frühjahr stammen, was darauf schließen läßt, daß Gametophyten und Sporophyten von Dictyota unter den gegebenen ökologischen Bedingungen überwintert hatten. Die schmalen und in einem weiten Winkel gegabelten Thallusenden an den alten Pflanzen erinnern an die als var. intricata oder var. implexa beschriebenen Formen. Wenn auch schmal bandförmige Pflanzen in wärmeren Meeresgebieten eine ansehnliche Länge erreichen, so ist ihre Abgrenzung von der typischen Form doch nur bedingt möglich. Auch in Kulturen kann man ähnliche in schmale Lappen geteilte Pflanzen erhalten.

Abb. 10. Sphacelaria nana. A: Aufrechte, wenig verzweigte Fäden. B: Kugelige unilokuläre Sporangien mit Rhizoiden. C: Kleine kurzgestielte plurilokuläre Sporangien. D: Lange plurilokuläre Sporangien auf mehrzelligen Stielen. Maßstrecken: $A=200 \mu \mathrm{m} ; \mathrm{B}, \mathrm{D}=100 \mu \mathrm{m}$ 


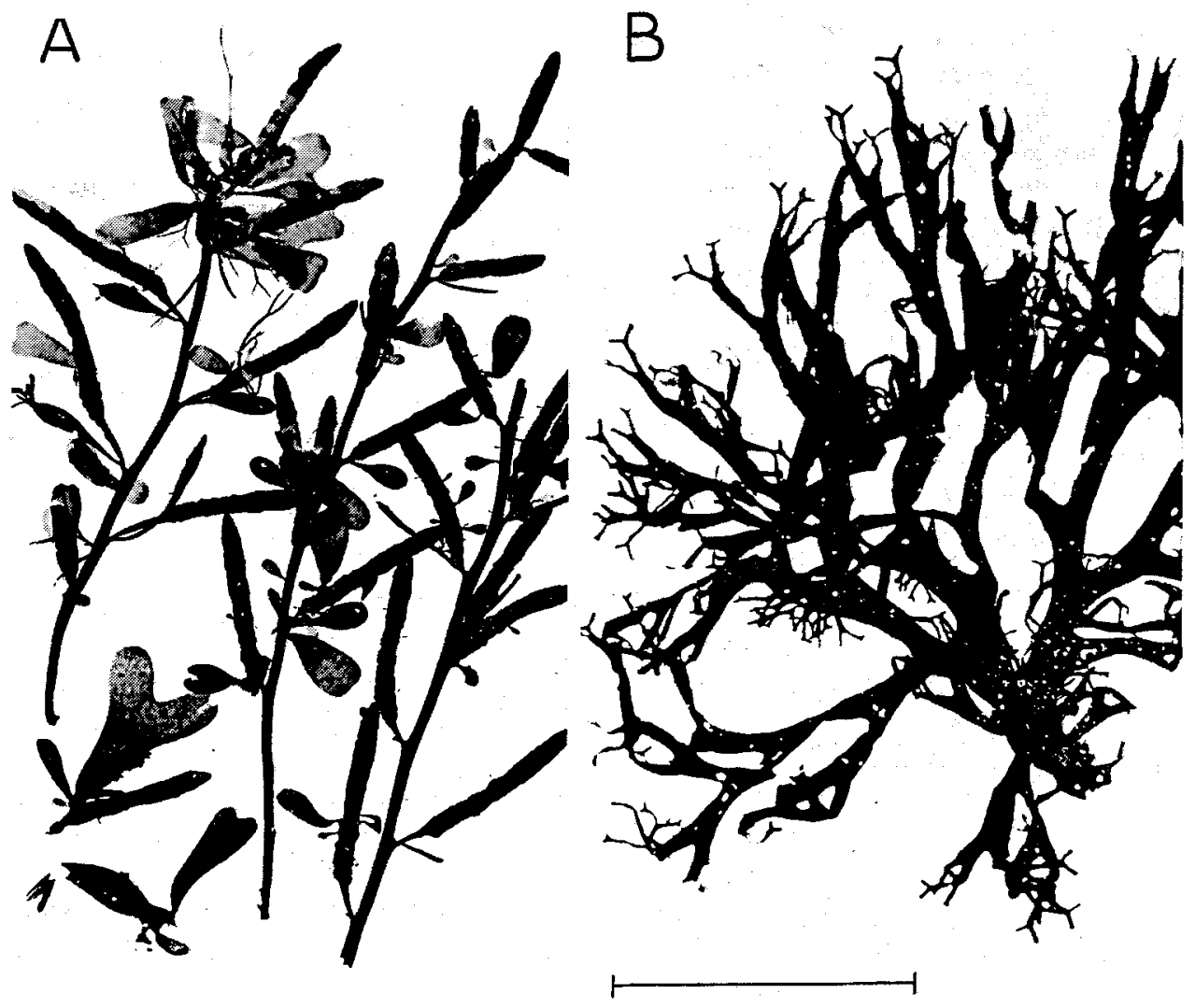

Abb. 11. Dictyota dichotoma. A: Bis zu 2,5 cm lange Keimlinge auf Sargassum muticum (September 1990). B: Überständiger Thallus, an den Enden lang und schmal ausgewachsen (Dezember 1989). A Natürliche Größe: B Maßstrecke $=5 \mathrm{~cm}$

Könnten vielleicht die früher auf dem Felswatt lebende Population und die heute im Sublitoral vorkommende verschiedene Ökotypen sein? Eine ungelöste Frage.

Fucus ceranoides L.

Am 23. April 1993 sammelte Rolf Karez eine in Helgoland unbekannte Art: Fucus ceranoides. Diese Alge wuchs auf Urgesteinsblöcken, die erst seit knapp einem Jahr der erneuerten Hafenmauer des Nordosthafens vor der Biologischen Anstalt vorgelagert sind (Abb.12A). Hier ist er dem täglichen Wechsel der Gezeiten ausgesetzt. Ein weiteres Vorkommen von $F$. ceranoides im marinen Milieu ist uns nicht bekannt.

Eine weitere Besonderheit zeigten Thalli vom 15. Mai. Einige dieser Pflanzen ent-

Abb. 12. Fucus ceranoides. A: Steinschüttung vor der Biologischen Anstalt, in deren Vegetationszone der für Helgoland neue Fucus erstmals am 23. April 1993 beobachtet wurde. B männliche, $C$ weibliche Pflanze, natürliche Größe 26 und $30 \mathrm{~cm}$ 

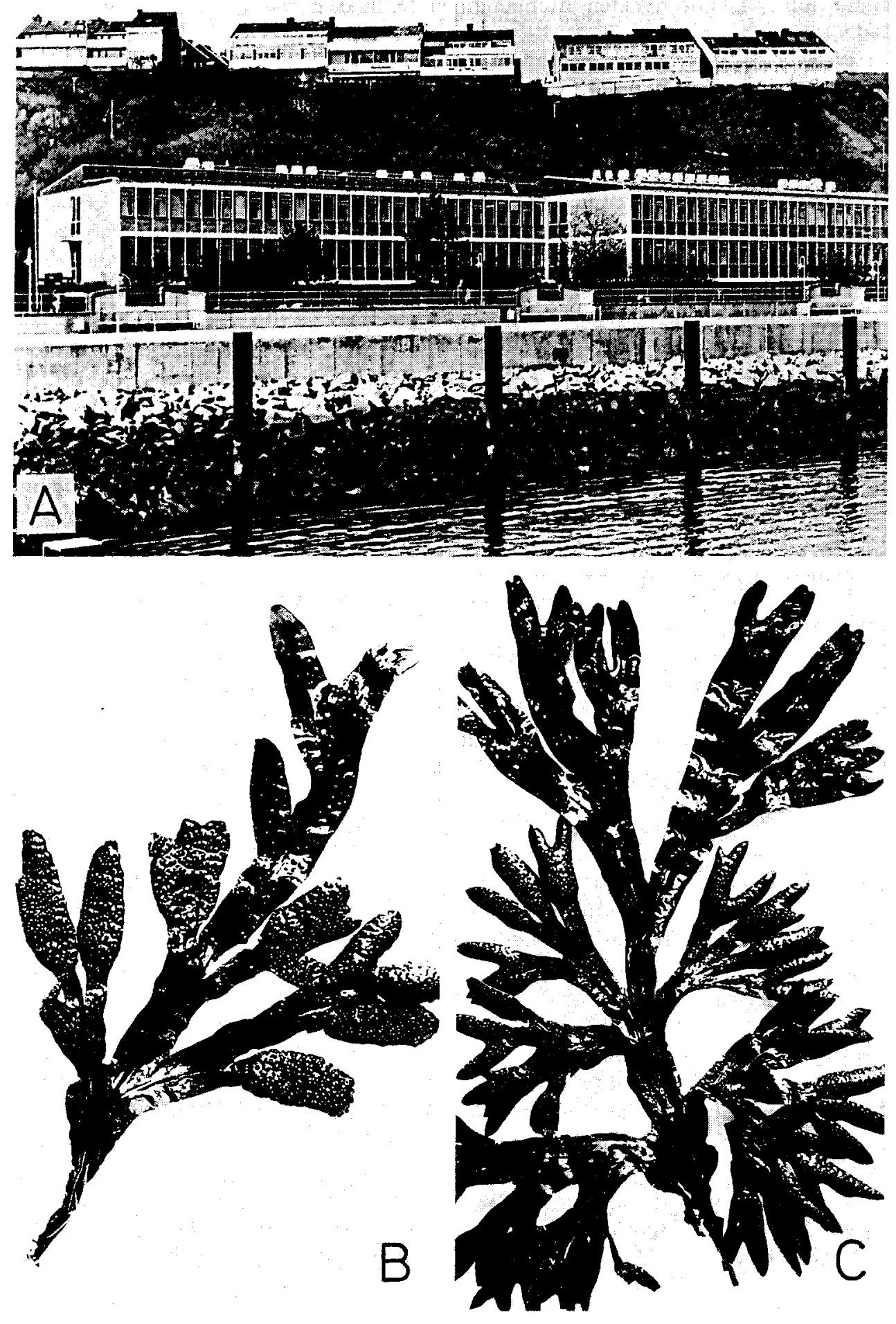
hielten außer langgestreckten Aufblähungen Luftblasen wie Fucus vesiculosus. Der Gedanke an eine mögliche Bastardierung liegt nahe.

Wann $F$. ceranoides sich bei Helgoland angesiedelt haben könnte, läßt sich nachträglich nicht klären, weil wir in den letzten fünf Jahren keine eigenen Exkursionen mehr unternehmen konnten. Während dieser Zeit war die Alge in dem Hafenbecken mit Sicherheit nicht vorhanden; das Becken wurde damals für Untersuchungen an Porphyra laufend kontrolliert. Wir können auch nichts darüber aussagen, wo sich die Alge sonst schon angesiedelt haben könnte. Bemerkenswert sind zwei Tatsachen: (1) Die sicherlich nicht aus einem vollmarinen Milieu stammende Alge konnte bei Helgoland Fuß fassen. (2) Das rasche Wachstum von $F$. ceranoides, der innerhalb eines Jahres die Steinblöcke mit einer dichten Vegetation überzog.

F. ceranoides ist im allgemeinen diözisch. An der nordfranzösischen Küste wachsen bei Dieppe einzelne zwittrige Pflanzen zusammen mit einhäusigen. In der Bucht von Saint-Malo sind die Pflanzen meist zwittrig (Hamel, 1931-1939).

F. ceranoides wird in der Literatur (Newton, 1931; Hamel, 1931-1939) als 10-50 cm lang und 0,5-2 $\mathrm{cm}$ breit beschrieben. Die kleine konische Haftscheibe ist an der Basis oft bis auf die erhabene zarte Mittelrippe reduziert. Die membranartigen Thalli haben keine Luftblasen, oft aber Aufblähungen, die sich über die ganze Länge einer Verzweigung erstrecken können. Die Rezeptakeln stehen in fächerförmigen Büscheln einseitig oder fiederig an der Achse. Sie sind schmal, abgeflacht und enden mit einer scharfen Spitze. Der Thallus kann leicht gewellt sein.

F. ceranoides lebt an Plätzen, wo Süßwasser kleiner Flüßchen in landnahe Buchten fließt. Es ist daher nicht verwunderlich, wenn die oben angegebenen Merkmale bei der Alge in dem vollmarinen Milieu Helgolands nicht klar zutage treten. Die Abbildungen $12 \mathrm{~B}$ und $\mathrm{C}$ zeigen eine männliche und weibliche Pflanze. Die nicht umrandeten Rezeptakel der männlichen Pflanze sind breit und stumpf. Bei der weiblichen Pflanze ist nur ein Teil der Rezeptakel zugespitzt. Eine weitere Bearbeitung können wir nicht mehr übernehmen und empfehlen einem jüngeren Mitarbeitèr, die Studie fortzusetzen.

\section{Sargassum muticum (Yendo) Fensholt}

Die Ansiedlung von Sargassum muticum bei Helgoland war zu erwarten, doch konnten festsitzende Pflanzen erst 1988 im Südhafen nahe der Ostmole bei Tauchgängen durch Udo Schilling und Hans Reichenberger nachgewiesen werden. Im Becken vor der Westmole des Vorhafens wurde S. muticum 1989 von Land aus durch Klaus Janke und auf einem Tauchgang durch Hans Reichenberger gefunden. Seit 1990 wird die Alge auch in tieferen Gezeitentümpeln auf dem Felswatt im Nordosten und der Südwestseite der Insel gefunden. Treibende Exemplare waren in der Deutschen Bucht schon öfter beobachtet worden, im August 1985 auch auf der Düne.

Kremer et al. (1983) haben die Reise dieser Alge um die Welt und ihr Eindringen in die Deutsche Bucht ausführlich dargestellt; hier mögen einige Stichworte genügen. Der

Abb. 13. Sargassum muticum, Helgoland. A: Thallus, unterer Teil mit langen gesägten Blättern (17. 8. 1992). B: fertiles Zweigende (5. 9. 1990). C: Endzweig mit reduzierten Blättchen, langgestreckten Rezeptakeln und kugeligen bis eiförmigen Schwimmblasen. D: Eier, auf Gallertstielchen an der Oberfläche der Rezeptakel haftend. E: Eier. F: Keimlinge mit Rhizoiden. Maßstrecken: $\mathrm{D}=1 \mathrm{~mm} ; \mathrm{E}, \mathrm{F}=200 \mu \mathrm{m}$ 

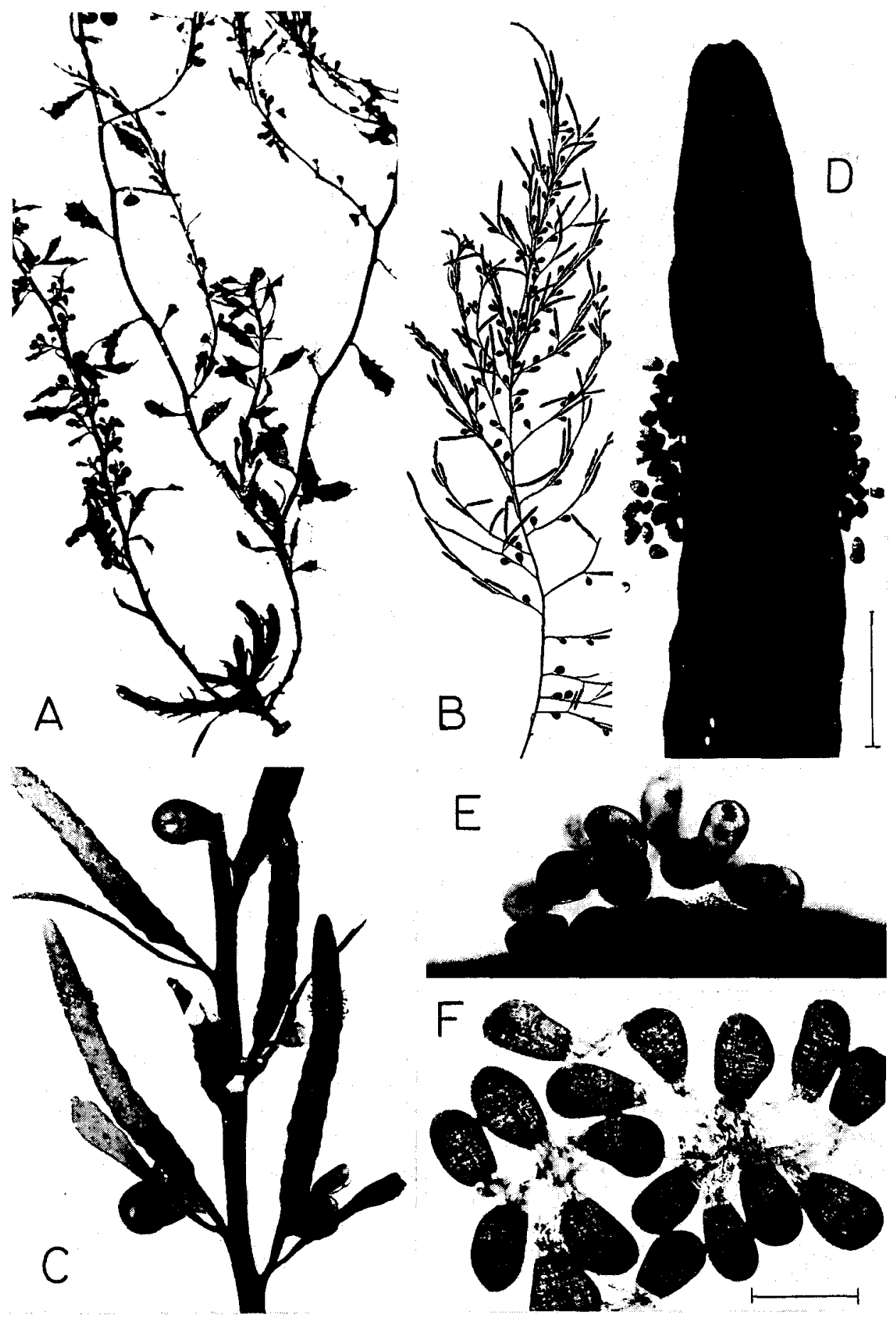
in Japan beheimatete Tang wurde um 1940 mit Zuchtaustern nach British Columbia und Washington eingeschleppt; er breitete sich rasch entlang der Pazifikküste südwärts über Kalifornien bis Neu Mexiko aus.

In Europa nahm die Einbürgerung dieser Alge 1972 von Austernkulturen an der französischen Kanalküste ihren Ausgang. Im Frühjahr 1973 trat S. muticum in England bei der Isle of Wight und Portsmouth auf. Alle Versuche, ihre Ausbreitung einzuschränken, waren erfolglos. Sie faßte an den englischen und französischen Kanalküsten Fuß, 1977 war das Rheindelta und 1980 die Insel Texel erreicht. In einer Liste der Algen Dänemarks von 1985 wird sie für den Limfjord angegeben (Christensen et al., 1985).

S. muticum ist eine ausdauernde Alge. Auf der überwinternden Basalscheibe erhebt sich meist nur ein aufrechter Sproß, der sich in einiger Höhe allseitig verzweigt und rasch zu einem büscheligen Thallus heranwächst. Nur in seinem unteren Teil ist der Sproß mit 2-2,5 cm langen schwach gesägten "Blättern" besetzt (Abb. $13 \mathrm{~A}$ ). Weiter nach oben werden sie immer kleiner und können schließlich an den reich fertilen Zweigenden lang flutender großer Pflanzen fehlen (Abb.13B). Im allgemeinen tragen die Endzweige zusammen mit einem reduzierten Blättchen die eiförmigen bis kugeligen Schwimmblasen und später auch die langgestreckten Rezeptakel (Abb. 13 C).

$S$. muticum ist monözisch. Die Konzeptakel enthalten getrennt Oogonien und Antheridien, jeweils mit einer eigenen Öffnung. Die entleerten Eier werden nicht abgelöst, sondern haften auf eigenen Gallertstielchen an der Oberfläche der Rezeptakel (Abb. 13D). Von ihren 8 Kernen bleibt nach der Befruchtung nur einer erhalten. Das Haften an der Mündung der Konzeptakel sichert die Befruchtung durch die nur kurzfristig beweglichen Spermatozoiden. Bis zur Entwicklung mehrzelliger Embryonen mit Rhizoiden verbleiben die Keimlinge an den Rezeptakeln, bevor sie abfallen und verdriftet werden. Die Ausbreitung der Alge wird also nicht nur durch die Verdriftung ganzer Pflanzen, sondern auch durch abgerissene fertile Zweigstücke und die schon "bewurzelten" Keimlinge wirkungsvoll unterstützt (Abb.13E; F).

Botrytella uvaeformis (Pringsh.) nov. comb.

Sorocarpus Pringsheim ist ein späteres Synonym von Botrytella Bory. Die typische Art wurde auf Lyngbyes Ectocarpus siliculosus var. uvaeformis gegründet. Es bedurfte zweier Arbeiten, um eine Übersicht über die Gattung Sorocarpus zu gewinnen (Kornmann \& Sahling, 1984, 1988). Sorocarpus uvaeformis Pringsheim ist in seinem Habitus und seiner Entwicklung von einer nicht definierten Art unterschieden. Außerdem wurde Ectocarpus (= Polytretus) reinboldii der Gattung Sorocarpus zugeführt. Dieses beinhaltete unsere Arbeit von 1984.

Fünf Jahre nach dem Erscheinen unserer letzten Arbeiten über Sorocarpus bzw. Botrytella (Kornmann \& Sahling, 1988) sind nochmals nomenklatorische Berichtigungen notwendig geworden. Hier soll zusammenfassend über den Status der Gattung Botrytella berichtet werden (Dieser Absatz erscheint unvollendet. Die Herausgeber). Botrytella uvaeformis (Pringsh.) nov.comb. ist der legitime Name für die seltene Art, deren typischer Fundort Helgoland ist: 


\section{ROTALGEN}

\section{Porphyra C. Ag. \\ Übersicht über die Arten}

Eine ausführliche Darstellung über die Porphyra-Arten Helgolands und ihre Taxonomie erschien vor wenigen Jahren (Kornmann \& Sahling, 1991: The Porphyra species of Helgoland - Bangiales, Rhodophyta). Die hier folgende Fassung soll in erster Linie den Teilnehmern an Kursen als Hilfe für die Identifizierung der Arten dienen. Auf morphologische und entwicklungsgeschichtliche Studien kann jedoch nicht verzichtet werden, um die Arten taxonomisch zu definieren und näheren Aufschluß über ihre Biologie zu erhalten. Dabei werden einige neu erkannte Zusammenhänge mitgeteilt.

Sieben Arten sind in der oben erwähnten Arbeit aufgeführt, von ihnen sind fünf in unseren "Meeresalgen" (Kornmann \& Sahling, 1977) mit Habitusbildern dargestellt. Jede Art nimmt den für sie spezifischen Lebensraum ein, entweder an den Uferschutzmauern oder auf dem Felswatt. An den Mauern - sie sind Steilküsten vergleichbar - unterliegen die Algen nicht nur dem mit den Gezeiten wechselnden Wasserstand, sondern sind auch in ganz unterschiedlichem Maße dem Wellenschlag ausgesetzt $t_{i}$ in den Hafenbecken werden sie nur leicht von anrollenden Wellen bewegt. Diese ökologischen Verschiedenheiten haben eine bei Porphyra besonders ausgeprägte Zonierung im Litoral zur Folge.

Die rundlich-lappigen Thalli von Porphyra umbilicalis (Kornmann \& Sahling 1977. Abb. 151) nehmen einen Gürtel von ungefähr $50 \mathrm{~cm}$ Breite unterhalb der Hochwasserlinie ein. An stark exponierten Stellen besiedelt diese Art auch mit kleineren, heller gefärbten Thalli die Spritzzone. Im oberen Litoral und der Spritzzone kommen in den Winter- und Frühjahrsmonaten auch die schlanken Thalli von Porphyra linearis vor; sie sind durch ihre Form nicht mit $P$. umbilicalis zu verwechseln (Kornmann \& Sahling, 1977, Abb. 152).

Im mittleren Litoral, aber deutlich von $P$. umbilicalis abgesetzt, hat Porphyra insolita ihren Platz, eine erst in unserer Studie von 1991 beschriebene und abgebildete Art. Es ist unwahrscheinlich, daß diese Alge, die einen dichten Gürtel großer lappiger Pflanzen bilden kann, früher unserer Beobachtung entgangen ist; vermutlich hat sie sich in den letzten Jahrzehnten hier angesiedelt und ausgebreitet. Die Grenze zum Sublitoral nehmen Porphyra ochotensis und Porphyra laciniata ein. P.ochotensis ist mit der in unseren früheren Arbeiten als Porphyra sp, bezeichneten Art identisch (Kornmann \& Sahling, 1977, Abb. 155). Porphyra laciniata war uns vor der gründlichen Revision der Gattung nicht bekannt; sie war auf Steinen am Fuße der Uferschutzmauer vor der Kurpromenade zusammen mit P.ochotensis in reichlicher Menge anzutreffen. Beide Arten können bisweilen völlig eingesandet werden. An diesem Mauerabschnitt fehlt allerdings $P$. insolita, die in dem benachbarten Nordosthafen dichte Bestände bildet.

Zwei auf dem Felswatt im Frühjahr und Sommer vorkommende Arten sind schon an äußeren Merkmalen leicht zu erkennen. Der meist langgestreckte Thallus von Porphyra purpureo-violacea ist durch eine scharfe mediane Linie in eine hellere und eine dunkler gefärbte Hälfte geteilt (Kornmann \& Sahling, 1977, Abb. 152). Sie kommt im mittleren Litoral besonders auf Steinblöcken vor. Fucus serratus trägt oft epiphytisch Porphyra leucosticta; ihr Erkennungsmerkmal wird schon durch den Namen zum Ausdruck gebracht, der auf die unregelmäßig in dem Thallus verteilten hellen Inseln der Spermatangien hinweist. 


\section{Zur Biologie von Porphyra}

Drew $(1949,1954)$ stellte den genetischen Zusammenhang der flächigen Porphyra mit der kalkbohrenden Conchocelis-Phase fest und öffnete damit den Weg für die Erforschung ihrer Biologie. Ihr Untersuchungsobjekt war Porphyra laciniata. Das Material enthielt Thalli mit gelblich-weißen Spermatangien und solche mit rötlich gefärbten Rändern, deren Sporen sich'zu Conchocelis entwickelten. Eine Befruchtung der Sporen konnte nicht festgestellt werden, was auch die zytologische Untersuchung des gleichen Materials durch Krishnamurthy (1959) bestätigte. Er stellte in den Sporen die Chromosomenzahl $\mathrm{n}=5$ fest, ebenso in den Spermatien und der Conchocelis-Phase.

Diese Besonderheit eines monophasischen, heteromorphen Zyklus gab zunächst Rätsel auf und verzögerte die Aufklärung der Biologie von Porphyra um Jahrzehnte: Die von Drew untersuchte Population von P. laciniata enthielt nämlich keine oder vielleicht nur ganz wenige weibliche Thalli. Daß sie vorhanden waren, ist nur ihrer kurzen Bemerkung zu entnehmen (Drew, 1955, p.6): "On one occasion I found cells with protrusions of considerable size and in many instances from both sides of the cell, and with genuine spermatia adhering to them." Das Studium der Helgoländer Population führte weiter; es enthielt neben den ungeschlechtlichen Thalli auch beiderlei Geschlechtspflanzen. Schon in der Aufsicht auf den reifen Thallus werden die Unterschiede deutlich; die ungeschlechtlichen Sporen liegen meist in Gruppen von vier Zellen zusammen (Kornmann \& Sahling, 1991, Abb. 14), während die Oberfläche des weiblichen Thallus Pakete von jeweils acht Karposporen zeigt (1991, Abb. 15). Auf Querschnitten werden die Unterschiede besonders deutlich; die jungen Karpogone setzen sich mit Trichogynen beiderseits in die blasig vorgewölbte Thallusoberfläche fort. Solche Stadien werden bei der Entstehung der ungeschlechtlichen Sporen nicht beobachtet. Erwartungsgemäß entwickeln sich die Karposporen zu einer diploiden Conchocelis-Generation; die Reduktionsteilung erfolgt wahrscheinlich bei der Keimung der Conchosporen.

Bei Porphyra laciniata existieren also zwei.heteromorphe Entwicklungszyklen nebeneinander, ein monophasischer mit nur ungeschlechtlichen Thalli und ein diphasischer, der Geschlechtspflanzen einschließt; zu dieser Erkenntnis führte die entwicklungsgeschichtliche Untersuchung der Helgoländer Population. Eine genetische Verbindung der geschlechtlichen und der ungeschlechtlichen Generation konnte nicht festgestellt werden.

Diesem Typus der Entwicklung folgen aber nicht alle Porphyra-Arten. Bei Porphyra umbilicalis, $P$. insolita und $P$. ochotensis gibt es zwar ebenfalls morphologisch gleichartige geschlechtliche und ungeschlechtliche Generationen nebeneinander, jedoch entwickeln sich bei diesen Arten die ungeschlechtlichen Sporen unmittelbar zu Porphyra. $\mathrm{Ob}$ und wie die jeweils morphologisch gleichen Generationen dieser Arten miteinander verbunden sind, ist ebenfalls nicht bekannt.

Die an Helgoländer Porphyra-Arten durch Kulturversuche erzielten Ergebnisse konnten auch an einem Paar nordpazifischer Arten bestätigt werden. Durch gelelektrophoretische Untersuchungen steliten Lindstrom \& Cole (1990) die Synonymie der Geschlechtsgeneration von Porphyra perforata und der ungeschlechtlichen Generation von P. sanjuanensis fest. An dieser Art wurde die direkte Entwicklung der in "sporocarps" gebildeten Sporen erstmals ausführlich dargestellt. Solche ungeschlechtlichen Sporen wurden später als Aplanosporen bezeichnet. Zur Unterscheidung von den in 
gleicher Weise entstandenen Sporen, die sich zu Conchocelis entwickeln, schlagen wir die Bezeichnung Agamosporen vor.

Auch die Spermatien der in so eindrucksvoller Weise monözisch erscheinenden Porphyra purpureo-violacea und P. leucosticta sind funktionslos. Die Aufsicht auf die als weiblich angesehenen reifen Thallusabschnitte zeigt jeweils vier aus einer Zelle entstandene Sporen. Sie liegen in zwei Schichten übereinander. Ihre Conchocelis-Generation führt über Conchosporen zu der flächigen Porphyra zurück. Der Entwicklungszyklus ist also heteromorph und monophasisch.

$P$. purpureo-violacea ist bisher nicht karyologisch untersucht; für P. leucosticta und andere Arten von gleichem Habitus wurde dieselbe Chromosomenzahl in allen Phasen der Entwicklung nachgewiesen (Kapraun \& Freshwater, 1987). Die Bezeichnung ihrer ungeschlechtlichen Sporen als Karposporen sollte daher vermieden und durch Agamosporen ersetzt werden.

Der Vollständigkeit wegen sei noch eine weitere Art von Sporen mit direkter Entwicklung erwähnt, die bisher als Monosporen bezeichnet, nach Magne (1991) als Archeosporen unterschieden werden müssen. Sie entstehen jeweils einzeln in einer Zelle des monostromatischen Thallus. An Naturmaterial der Helgoländer Arten wurden sie nicht beobachtet, nur in Jugendstadien von $P$. leucosticta im Kulturexperiment. Bei einigen japanischen Arten tragen sie auch wesentlich zur Vermehrung großer Thalli bei.

Eine ausführlichere Darstellung der Entwicklungszyklen von Porphyra findet sich bei Kornmann (1994; posthum veröffentlicht).

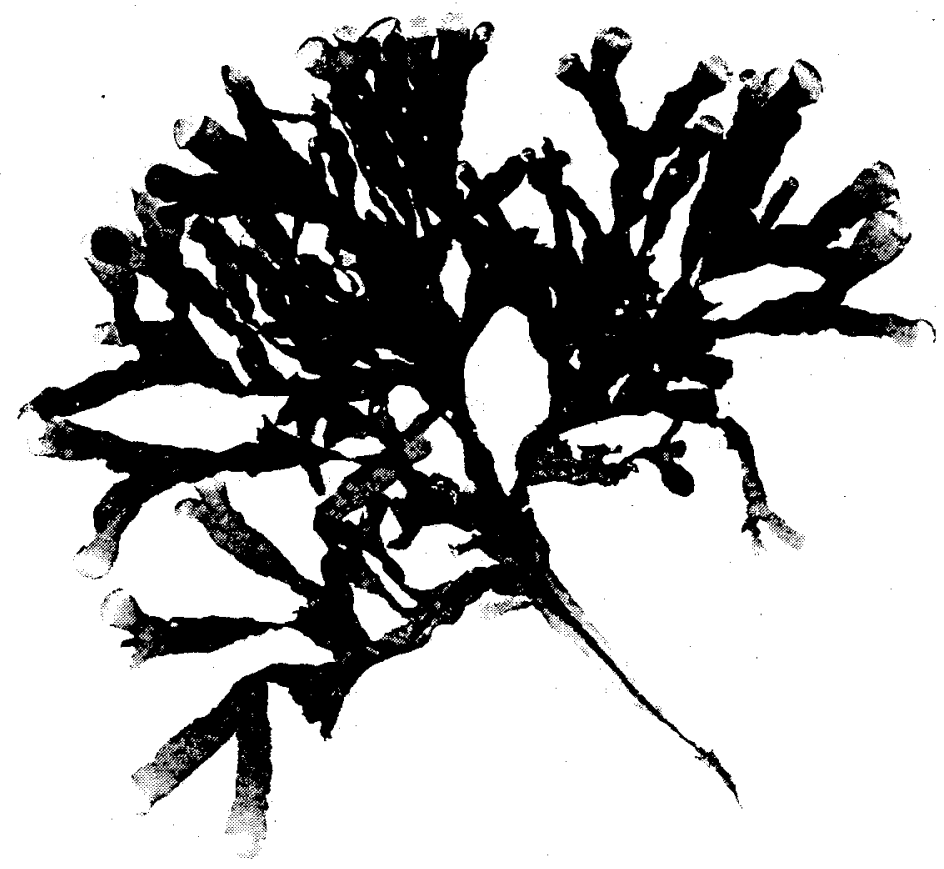

Abb. 14. Phyllophora crispa, Helgoland (19. 12. 1990). Thallus in natürlicher Größe aus 4-6 m Tiefe 


\section{Erythropeltidaceae}

Über diese Familie berichteten Kornmann \& Sahling (1985) mit einem Bestimmungsschlüssel der Gattungen. Von diesen sind Erythropeltis Rosenvinge und Erythrotrichopeltis (Kornmann, 1984) wieder ausgeschieden, Erythrotrichia subintegra (Rosenvinge) wurde in die Gattung Sahlingia überführt (Kornmann, 1989).

Sicherlich ist Porphyrostromium (= Erythrotrichopeltis) ciliare (Carm. ex Harv.) Wynne eine der interessantesten Helgoländer Algen. Das Kulturexperiment ergab, daß ihr heteromorpher Lebenszyklus das scheibenförmige (peltoide) Sporophytenstadium Erythropeltis discigera (Berth.) Schmitz und das flächige (trichoide) Stadium Erythrotrichia ciliaris (Carm.) Batters einschließt (Kornmann, 1984). Aus nomenklatorischen Gründen mußte dieser Gattungsname dem älteren Porphyrostromium Trevisan (1848) weichen (Wynne, 1986). Damit war auch die Basis für die Selbständigkeit von Erythrocladia subintegra hinfällig, und Erythropeltis schied als selbständige Gattung aus (Kornmann, 1989).

Phyllophora crispa (Huds.) Dixon syn P. rubens (Good. et Woodw.) Grev.

Diese längs der europäischen Atlantikküsten verbreitete Alge fehlt auch nicht bei Helgoland. In allen Auflagen des "Strandwanderers" wird ihr seltenes Vorkommen "in tieferem Wasser" angegeben (Kuckuck, 1905). Das bedarf einer Einschränkung. Nur im Herbarium Kuckuck werden bisher zahlreiche Exemplare aus Dredschmaterial von 1893 und 1900 verwahrt. Sie wurden während des ganzen Jahres im Nordhafen und Skitgat in 6-10 m Tiefe erbeutet. Diese Thalli tragen einen starken Bewuchs von Bryozoen.

Erst im Dezember 1990 und November 1991 konnten mehrere 8-10 cm große Pflanzen von Tauchern in 4-6 m Tiefe im Nordwesten der Insel in der "Weißen Rinne" gefunden werden. Dennoch spricht nichts dagegen, daß die Alge nicht immer vorhanden war. Diese Pflanzen waren völlig sauber; in dem gestieiten älteren Teil ist eine Mittelrippe gut zu erkennen (Abb.14). Aus seinen Enden sproßt das lebhaft rot gefärbte, dichotom geteilte junge Laub.

\section{Mastocarpus stellatus (Stackh. in With.) Guiry syn. Gigartina stellata (Stackh.) Batters}

Wer heute dem kilometerlangen dichten Saum von Mastocarpus stellatus vor der Uferschutzmauer im Südwesten der Insel gegenübersteht, wird es kaum für möglich halten, daß diese Alge dort erstmals am 2. August 1983 festgestellt wurde. Damals waren es wenige Büschel in einem kleinen Bereich des Felswatts nahe dem Ende der Uferschutzmauer (Abb. 15 A). Feldversuche von Dr. I. Munda (persönliche Mitteilung) in den siebziger Jahren mit Material aus Island haben zur Einbürgerung der Alge geführt; sie war sicherlich nicht beabsichtigt und auch nicht vorauszusehen. Der Einwanderer fand an den der Uferschutzmauer vorgelagerten Granit- und Basaltblöcken sowie an Betontrümmern das notwendige harte Substrat. Längeres Trockenliegen während der sehr

Abb. 15. Mastocarpus stellatus. A: Standortaufnahme (27. 8. 1983). Büschel auf den der Uferschutzmauer vorgelagerten Granitblöcken. B: typische, fruktifizierende Pflanze mit vielen Papillen auf der Oberfläche, Basalteil rinnig gefurcht. C: jüngere Pflanzen mit ersten Papillen. D: junger Thallus. 

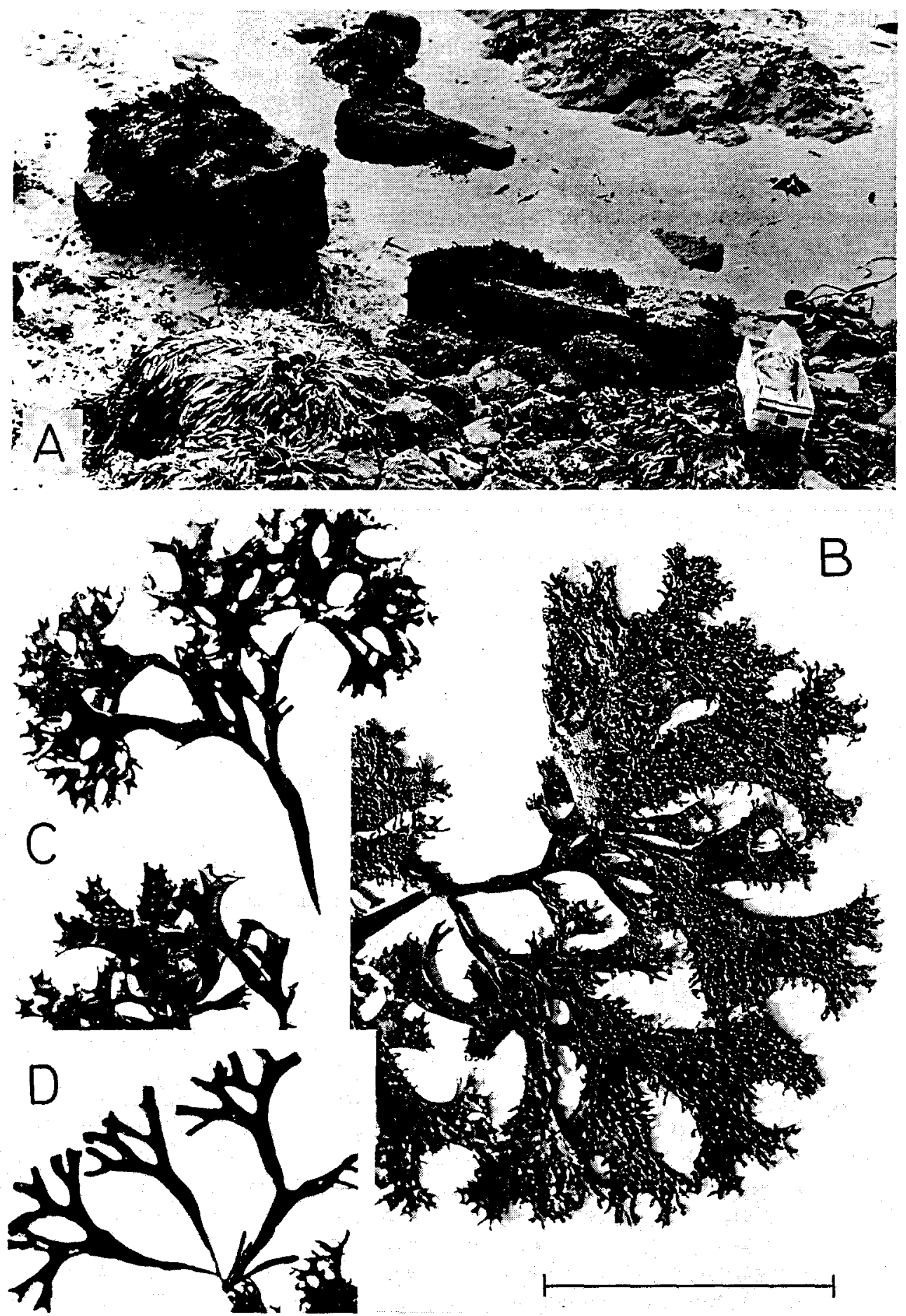
kalten Winter 1986 und 1987 wurde schadlos überstanden. Die rasche Ausbreitung innerhalb eines Jahrzehnts erfolgte mittels ungeschlechtlicher Sporen aus Behältern, die morphologisch den Karposporangien diözischer Populationen der Alge entsprechen. Im Februar 1993 wurde Mastocarpus erstmals auf der Nordostseite der Insel gefunden: an Betontrümmern auf dem Felswatt und an mehreren Stellen der Ostmole.

Die dichten, krausen, knorpeligen Büschel werden bis zu $10 \mathrm{~cm}$ hoch, ihre dichotomen Thallusteile etwa $1 \mathrm{~cm}$ breit. Ältere Thalli können von Bryozoen oder einzelnen Seepocken besiedelt sein. Die im Sommer fruktifizierenden Pflanzen sind unverkennbar durch die zahlreichen Papillen auf ihrer Oberfläche, in deren Enden die Sporen gebildet werden (Abb. 15B). Vegetative oder junge Exemplare könnten mit Chondrus crispus verwechselt werden, der jedoch ein etwas tieferes Niveau im Litoral einnimmt. Ein deutlicher morphologischer Unterschied ist der rinnig gefurchte Basalteil des Mastocarpus-Thallus (Abb. 15 C, D). Dieses Material sowie die Papillen der weiblichen Pflanzen kennzeichnen die Gattung Mastocarpus und waren der Grund für die Abtrennung von Gigartina.

M. stellatus ist längs der europäischen Küsten weit verbreitet (Guiry \& West, 1983). Sie kommt an der Kanalküste, an exponierten Standorten in den Niederlanden wie auch an Hafenmolen im Skagerrak und an der Küste von Südnorwegen vor. Es ist daher verständlich, daß Guiry \& West (1983) ausdrücklich auf ihr Fehlen bei Helgoland hinweisen. Die Erklärung dafür liegt nahe: lange Zeit fehlte das für ihr Vorkommen geeignete Substrat. Nach Anfang der 50er Jahre blieben harte Gesteinsbrocken als Wellenbrecher vor der erneuerten Uferschutzmauer liegen. Während dieser Zeit wäre wohl auch eine natürliche Besiedelung, etwa durch treibende Sporen, möglich gewesen.

Entwicklungsgeschichtliche Untersuchungen von Guiry \& West (1983) mit vielen längs der europäischen Küsten gesammelten Proben von M. stellatus ergaben zwei Typen mit verschiedenem Lebenszyklus. Populationen von Island und Dänemark entwickelten sich ausschließlich direkt zu Generationen gleichartiger folioser Thalli. Populationen von Spanien und Portugal haben einen heteromorphen Wechsel von Geschlechtspflanzen mit einem krustenförmigen Petrocelis-artigen Tetrasporophyten. In Herkünften von den Küsten Frankreichs, Englands und Irlands wurden beide Typen der Entwicklung festgestellt.

Mastocarpus stellatus und Chondrus crispus sind an den Atlantikküsten Europas und Kanadas, wo sie in größeren Mengen vorkommen, als Rohstoff für die Gewinnung von Carrageen oder Irländisch Moos von erheblicher wirtschaftlicher Bedeutung. Ihr Inhaltsstoff, das Carrageenan, findet besonders in der Nahrungsmittel- und pharmazeutischen Industrie Verwendung.

\section{Antithamnionella floccosa (O. F. Müll.) Whittick}

Antithamnionella floccosa, im arktisch-subarktischen Areal beheimatet, ist eine der seltensten Arten aus dieser Region bei Helgoland. Während andere in der Arktis vorkommende Arten wie Pilayella macrocarpa (Kornmann, 1990) und Rhodomela virgata (Kornmann \& Sahling 1977, S. 254) reichlich bei Helgoland vorkommen, ist es ein reiner Zufall, wenn einmal $A$. floccosa oder Urospora curvata (siehe oben) beobachtet werden.

Nur einmal - am 12. Mai 1987 - wurden zahlreiche Fragmente von A. floccosa im Plankton treibend gefunden. Es liegt nahe, ihr Auftreten auf die über längere Zeit anhaltenden niedrigen Wassertemperaturen in den Jahren 1986 und 1987 zurückzufüh- 

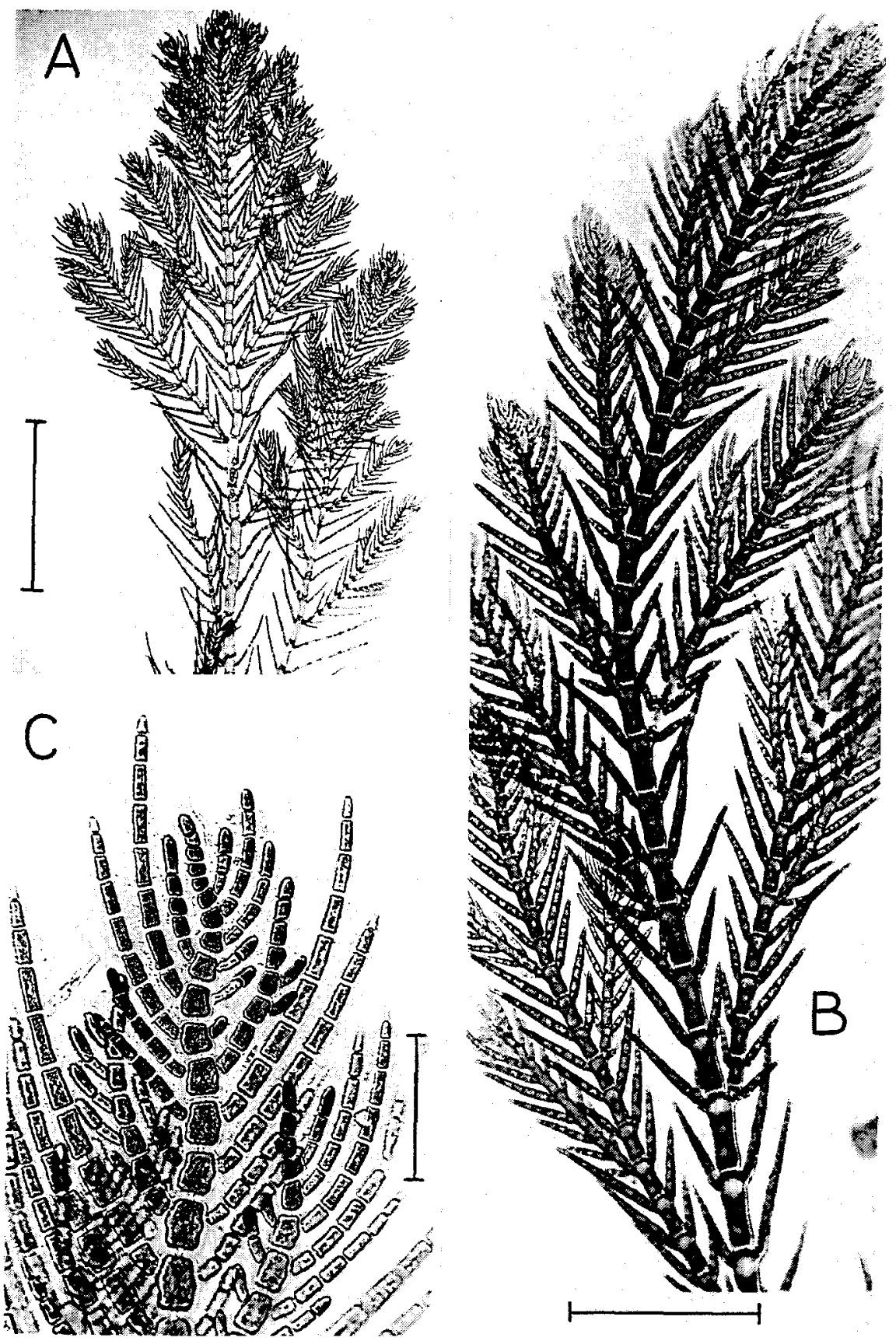

Abb. 16. Antithamnionella floccosa, Helgoland, 12. 5. 1987. A, B: Aufbau. C: Spitzenregion. Maßstrecken: $\mathrm{A}=1 \mathrm{~mm} ; \mathrm{B}=0,5 \mathrm{~mm} ; \mathrm{C}=100 \mu \mathrm{m}$ 
ren, in denen die Mittelwerte im Februar und März bei $1^{\circ} \mathrm{C}$ bzw. $1,7^{\circ} \mathrm{C}$ lagen. Vermutlich ist die Alge in reduzierter Form stets im Sublitoral vorhanden, doch kommt sie nur bei entsprechenden hydrographischen Bedingungen zur Entwicklung.

An den europäischen Küsten erreicht $A$. floccosa ihre Südgrenze im Norden von Irland, in Norwegen bei Bergen (Jacobsen et al., 1991). Helgoland ist also auch in biogeographischer Hinsicht eine Insel, ein kleines lokales Gebiet in der kaltgemäßigten Region, das mehreren arktisch-subarktischen Arten die entsprechenden hydrographischen Bedingungen bietet.

Über Aufbau und Fortpflanzung von A.floccosa hat Whittick (1980) ausführlich berichtet. Der taxonomischen Aufgliederung einiger antithamnoiden Gattungen der Ceramiaceen liegt der morphologische Aufbau der Spitzenregion zugrunde. Dadurch wurde die bei Helgoland häufige Antithamnion plumula (Kornmann \& Sahling 1977, S. 288) der Gattung Pterothamnion als P. plumula (Ell.) Näg. zugeführt (Moe \& Silva, 1980).

Unsere Abbildung 16 kennzeichnet die Merkmale der Gattung Antithamnionella. Die Thalli sind in einer Ebene verzweigt. Jede Achsenzelle trägt ein Paar gegenständiger ungleicher Seitenzweige. An der Spitze entspringen der jungen Achse aus benachbarten Zellen gleichzeitig meist drei einseitswendige Zweige abwechselnd nach links und rechts. Jeweils ein Zweig jeder Gruppe verzweigt sich nach dem Muster der Hauptachse (Abb. 16 C). Alle Fragmente aus mehreren Planktonproben waren steril.

\section{Polysiphonia lanosa (L.) Tandy syn. P. fastigiata}

Am Ende der Westmole ist zwischen der Mauer des Vorhafens und den als Wellenbrecher vorgelagerten Trümmern der früheren, durch Kriegseinwirkung zerstörten Hafenmauer ein etwa $15 \mathrm{~m}$ breites Becken entstanden. Es ist selbst für Taucher nur schwer zugänglich, birgt aber einige für Helgoland bemerkenswerte Algen.

In diesem Bereich wurden die ersten Exemplare von Sargassum muticum gefunden, und Dictyota dichotoma hat dort ein Reservat. Eine Besonderheit ist aber die erstmalige Beobachtung von Polysiphonia lanosa, eines auf Ascophyllum nodosum obligaten Epiphyten bei Helgoland.

Bisher ist $P$. Ianosa auf den festsitzenden Pflanzen im Bereich des Vorhafens, wo sich Ascophyllum in den letzten Jahren stark ausgebreitet hat, noch nicht gefunden worden. Dagegen tragen verdriftete Ascophyllum-Thalli häufig auch den Epiphyten. Die Einbürgerung der längs der europäischen Atlantikküsten gemeinen Alge bei Helgoland ist offensichtlich durch die lokalen Gegebenheiten möglich geworden. In das schmale Becken vor der Hafenmauer übergeschlagene treibende Algen können längere Zeit dort verweilen und den reichlich vorhandenen Ascophyllum-Bestand mit Tetrasporen oder Karposporen infizieren.

Polysiphonia lanosa bildet etwa $3-4 \mathrm{~cm}$ hohe dichte Büschel von dunkelroter bis schwarzer Färbung (Abb.17 A). Der dichotom verzweigte Thallus hat niedrigere Seg-

Abb. 17. Polysiphonia lanosa (September 1990). A: auf Ascophyllum nodosum. B: Die große Zentralzelle, von 12-24 Perizentralen umgeben, ist gut erkennbar. C: Tetrasporangien (August 1992). D: Antheridien. E: Karpogone. Maßstrecken: A Natürliche Größe; B $=200 \mu \mathrm{m}_{i}$ C, D, $=0,5 \mathrm{~mm}$; $\mathrm{E}=1 \mathrm{~mm}$. 

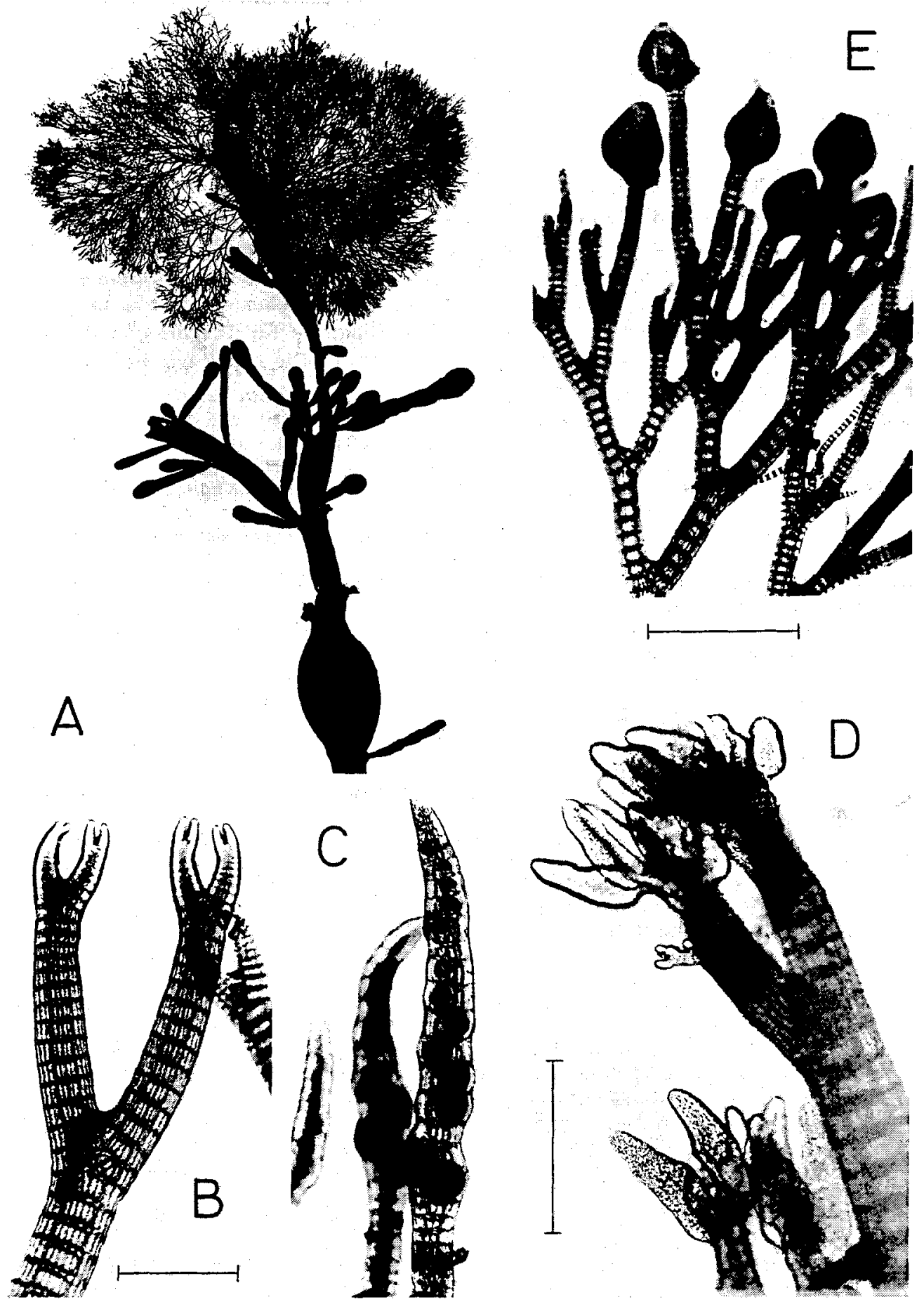
mente als die meisten anderen Polysiphonia-Arten. Die große Zentralzelle - sie schimmert in Abbildung $17 \mathrm{~B}$ gut erkennbar durch - ist von 12 bis 24 Perizentralen umgeben. Material vom September 1990 enthielt sterile Thalli und beiderlei Geschlechtspflanzen; inzwischen sind auch Tetrasporangien gefunden worden (Abb.17 C). Antheridien und Karpogone sitzen ohne Trichoblasten an den Thallusenden (Abb. 17 D, E).

\section{NACHWORT}

Peter Kornmann starb am 20. August 1993. Er hatte den Textteil der vorliegenden Arbeit vollendet, mit Ausnahme der Legenden und der Diagnose für Ulva tenera. Alle Tafeln, von Paul-Heinz Sahling gefertigt, lagen zu Lebzeiten von Peter Kormmann vor. Die Legenden wurden von Frau Hilde Kornmann geschrieben, ebenso - in enger Anlehnung an den Autorentext - die deutsche Diagnose für U.tenera, wobei die lateinische Fassung hierfür von Dr. Bruno Kremer stammt. Die Arbeit wurde ediert von Klaus Lüning, Ludwig Kies und Inka Bartsch.

\section{LITERATUR}

Ardré, F., 1970. Contribution à l'étude des algues marines du Portugal. I. La flore. - Port. Acta Biol. (B) $10(1-4), 137-555$.

Bliding, C., 1960. A preliminary report on some new Mediterranean green algae. - Bot. Notiser 113, 172-184.

Bliding, C., 1968. A critical survey of European taxa in Ulvalves. Part. II. Ulva, Ulvaria, Monostroma, Kornmannia. - Bot. Notiser 121, 535-629.

Christensen, T., Koch, D. \& Thomsen, H. A., 1985. Distribution of algae in Danish salt and brackish waters. Institut for Sporeplanter, København, $64 \mathrm{pp}$.

Correa, J. A., Nielsen, R. \& Grund, D. W., 1988. Endophytic algae of Chondrus crispus (Rhodophyta). II. Acrochaete heterocladia sp. nov., A. operculata sp. nov., and Phaeophila dendroides (Chlorophyta). - J. Phycol. 24, 528-539.

Dangeard, P., 1957. Sur deux espèces nouvelles d'Ulvacées de Côte Occidentale du Maroc. - C.r. hebd. Séanc. Acad. Sci., Paris 244, 1589-1592.

Drew, K. M., 1949. Conchocelis phase in the life-history of Porphyra umbilicalis (L.) Kütz. - Nature, Lond. 164, 748-749.

Drew, K. M., 1954. Studies in the Bangioideae. III. Life-history of Porphyra umbilicalis (L.) Kütz. var. laciniata (Lightf.) J. Ag. - Ann. Bot. 18, 183-211.

Drew, K. M., 1955. Phycology and the British phycological Society. - Phycol. Bull. 1, 1-10.

Feldmann, J., 1954. Inventaire de la flore marine de Roscoff: Algues, Lichens et Spermatophytes. Trav. Stn biol. Roscoff (N. S.) 5, Suppl. 6, 1-152.

Gayral, P., 1959-1960. Premières observations et réflexions sur des Ulvacèes en culture. - Botaniste $43,85-100$.

Golden, L. \& Garbary, D., 1984. Studies on Monostroma (Monostromaceae, Chlorophyta) in British Columbia with emphasis on spore release. - Jap. J. Phycol. 32, 319-332.

Guiry, M.D. \& West, J.A., 1983. Life history and hybridization studies on Gigartina stellata and Petrocelis cruenta (Rhodophyta) in the North Atlantic. - J. Phycol. 19, 474-494.

Hamel, G., 1931-1939. Phéophycées de France. Wolf, Paris, 432 pp.

Hickel, W., Mangelsdorf, P. \& Berg, J., 1993. The human impact in the German Bight: eutrophication during three decades (1962-1991). - Helgoländer Meeresunters. 47, 243-263.

Kapraun, D. F. \& Freshwater, D. W., 1987. Karyological studies of five species of Porphyra (Bangiales, Rhodophyta) from the North Atlantic and Mediterranean. - Phycologia 26, 82-87.

Jaasund, E., 1965. Aspects of the marine algal vegetation of North Norway. - Botanica Gothoburg. 4, $1-174$.

Jacobsen, T., Rueness, J. \& Athanasiadis, A., 1991. Antithamnionella floccosa (Rhodophyta) in culture: distribution, life history and chromosome number. - Botanica mar. 34, 491-499. 
Kjellman, F. R., 1883. The algae of the Arctic Sea. Kongl. Boktryckeriet, Stockholm, 350 pp.

Krishnamurthy, V., 1959. Cytological investigations on Porphyra umbilicalis (L.). Kütz. var. laciniata (Lightf.) J. Ag. - Ann. Bot. 23,147-176.

Koeman, R.P.T. \& Hoek, C. van den, 1981. The taxonomy of Ulva (Chlorophyceae) in the Netherlands. - Br. phycol. J. 16, 9-53.

Koeman, R.P.T. \& Hoek, C. van den, 1982a. The taxonomy of Enteromorpha Link, 1820 (Chlorophyta) in the Netherlands. I. The section Enteromorpha. - Arch. Hydrobiol. (Suppl.) 63, 279-330.

Koeman, R. P. T. \& Hoek, C. van den, 1982b. The taxonomy of Enteromorpha Link, 1820 (Chlorophyta) in the Netherlands. II. The section Proliferae. - Cryptogamie Algol. 3, 37-70.

Koeman, R. P. T. \& Hoek, C. van den, 1984. The taxonomy of Enteromorpha Link, 1820 (Chlorophyta) in the Netherlands. III. The Sections Flexuosae and Clathratae and an addition to the Section Proliferae. - Cryptogamie Algol, 5, 21-61.

Kornmann, P., 1984. Erythrotrichopeltis, eine neue Gattung der Erythropeltidaceae (Rhodophyceae - Bangiophycidae). - Helgoländer Meeresunters. 38, 207-224.

Kornmann, P., 1989. Sahlingia nov. gen. based on Erythrocladia subintegra (Erythropeltidales, Rhodophyta). - Br. phycol. J, 24, 223-228.

Kornmann, P., 1990. Pilayella macrocarpa Foslie (Ectocarpales, Phaeophyceae) in Helgoland and the rejection of Pilayella varia Kjellm. - Botanica mar. 33, 257-259.

Kornmann, P., 1994. Life histories of monostromatic Porphyra species as a basis for taxonomy and classification. - Europ. J. Phycol. 29, 69-71.

Kornmann, P. \& Sahling, P.-H., 1962a. Geschlechtspflanzen von Bonnemaisonia hamifera Hariot bei Helgoland. - Helgoländer wiss. Meeresunters. 8, 298-301.

Kornmann, P. \& Sahling, P.-H., 1962b. Zur Taxonomie und Entwicklung der Monostroma-Arten von Helgoland. - Helgoländer wiss. Meeresunters. 8, 302-320.

Kornmann, P. \& Sahling, P.-H., 1977. Meeresalgen von Helgoland. Benthische Grün-, Braun- und Rotalgen. - Helgoländer wiss. Meeresunters. 29, 1-289.

Kornmann, P. \& Sahling, P.-H., 1980. Kalkbohrende Mikrothalli bei Helminthocladia und Scinaia. Helgoländer Meeresunters. 34, 31-40.

Kornmann, P. \& Sahling, P.-H., 1983. Meeresalgen von Helgoland: Ergänzung. - Helgoländer Meeresunters. 36, 1-65.

Kornmann, P. \& Sahling, P.-H., 1984. Der Sorocarpus-Komplex (Ectocarpaceae, Phaeophyta). Helgoländer Meeresunters. 38, 87-101.

Kornmann, P. \& Sahling, P.-H., 1985. Erythropeltidaceen (Bangiophyceae, Rhodophyta) von Helgoland. - Helgoländer Meeresunters. 39, 213-236.

Kornmann, P. \& Sahling, P.-H., 1988. Die Entwicklung des Botrytella (Sorocarpus)-Komplexes (Ectocarpaceae, Phaeophyta). - Helgoländer Meeresunters. 42, 1-12.

Kormmann, P. \& Sahling, P.-H., 1991. The Porphyra species of Helgoland (Bangiales, Rhodophyta). Helgoländer Meeresunters, 45, 1-38.

Kremer, B.P., Kuhbier, H. \& Michaelis, H., 1983. Die Ausbreitung des Brauntangs Sargassum muticum in der Nordsee. - Natur Mus., Frankf. 113, 125-130.

Kuckuck, P., 1894. Bemerkungen zur marinen Algenvegetation von Helgoland. - Wiss. Meeresunters. (Helgoland) 1, 225-263.

Kuckuck, P., 1897a. Beiträge zur Kenntnis der Meeresalgen. 1. Über Rhododermis parasitica Batters. - 2. Über Rhodochorton membranaceum Magnus, eine chitinbewohnende Alge. - 3. Die Gattung Mikrosyphar Kuckuck. - 4. Über zwei höhlenbewohnende Phaeosporeen. - Wiss. Meeresunters. (Helgoland) 2, 329-370.

Kuckuck, P., 1897b. Bemerkungen zur marinen Algenvegetation von Helgoland. II. - Wiss. Meeresunters. (Helgoland) 2, 272-400.

Kuckuck, P., 1905. Der Strandwanderer. Lehmann, München, 76 pp.

Kützing, F.T., 1845. Phycologia Germania, d.i. Deutschland Algen in bündigen Beschreibungen Höhne, Nordhausen, 344 pp.

Kylin, H., 1935. Über einige kalkbohrende Chlorophyceen. - K. fysiogr. Sällsk. Lund Förh. 5 (19), 1-19 u. 186-204

Lindstrom, S.C. \& Cole, K.M., 1990a. Porphyra fallax, a new species of Rhodophyta from British Columbia and northern Washington. - Jap. J. Phycol. 38, 371-376.

Lindstrom, S.C. \& Cole, K.M., 1990b. An evaluation of species relationships in the Porphyra 
perforata complex (Bangiales, Rhodophyta) using starch gel electophoresis. - Hydrobiologia 204/ 205, 179-183.

Lüning, K., 1970. Tauchuntersuchungen zur Vertikalverteilung der sublitoralen Helgoländer Algenvegetation. - Helgoländer wiss. Meeresuntersuchungen 21, 271-291.

Magne, F., 1991. Classification and phylogeny in the lower Rhodophyta: a new proposal. - J. Phycol. 27 (Suppl.), 46.

Moe, R. L. \& Silva, P.C., 1980. Morphological and taxonomical studies on Antarctic Ceramiaceae (Rhodophyceae) II. Pterothamnion antarcticum comb. nov. Antithamnion antarcticum Kylin). Br. phycol. J, 15, 1-17.

Moestrup, O., Nicolaisen, S., Nielsen, H. \& Pedersen, P. M., 1975. Some new or noteworthy marine benthic algae from Denmark. - Bot. Tidsskr. 69, 257-261.

Mollenhauer, D. \& Lüning, K., 1988. Helgoland und die Erforschung der marinen Benthosalgen. Helgoländer Meeresunters. 42, 385-425.

Newton, L., 1931. A handbook of the British seaweeds. British Museum (Natural History), London, $487 \mathrm{pp}$.

Nielsen, R., 1972. A study of the shell-boring marine algae around the Danish island Laesø. - Bot. Tidsskr. 67, 245-269.

Nielsen, R., 1980. A comparative study of five marine Chaetophoraceae. - Br. phycol. J. 15, 131-138.

Nielsen, R., 1984. Epicladia flustrae, E. phillipsii stat. nov., and Pseudendoclonium dynamenae sp. nov. living in bryozoans and a hydroid. - Br. phycol. J. 19, 371-379.

Nienburg, W., 1925. Die Besiedelung des Felsstrandes und der Klippen von Helgoland. 2. Die Algen.Wiss. Meeresunters. (Helgoland) 15 (19), 1-15.

O'Kelly, C. J., Floyd, G.L. \& Dube, M.A., 1984. The fine structure of motile cells in the genera Ulvaria und Monostroma, with special reference to the taxonomic position of Monostroma oxyspermum (Ulvaphyceae, Chlorophyta.). - Pl. Syst. Evol. 144, 179-199.

Papenfuss, G.F., 1960. On the genera of the Ulvales and the status of the order. - J. Linn. Soc. (Botany) $56(367), 303-318$.

Printz, H., 1926. Die Algenvegetation des Trondjemfjordes. - Skr. norske VidenskAkad. (Mat.-natur. Kl.) $5,1-274$.

Prud'homme van Reine, W.F., 1982. A taxonomic revision of the European Sphacelariaceae (Sphacelariales, Phaeophyceae). - Leiden bot. Ser. 6, 1-293.

Radach, G., Berg, J. \& Hagmeier, E., 1990. Long-term changes of the annual cycles of meteorological, hydrographic, nutrient and phytoplankton time series at Helgoland and at LV Elbe 1 in the German Bight. - Cont. Shelf Res. 10, 305-328.

Reinke, J., 1891. Die braunen und rothen Algen von Helgoland. - Ber. dt. bot. Ges. 9, 271-273.

Schiller, J., 1928. Ulva curvata Kütz, und Porphyra linearis Grev., zwei für Helgoland neue Meeresalgen. - Hedwigia 68, 115-118.

Schmidt, O.C., 1928. Die Algenvegetation Helgolands. In: Vegetationsbilder 19 (5). Hrsg. von G. Karsten. Fischer, Jena, Taf. 25-30.

Schmidt, O.C., 1936. Neve oder bemerkenswerte Meeresalgen aus Helgoland I. - Hedwigia 75, 150-158.

Schmidt, O.C., 1938. Neue oder bemerkenswerte Meeresalgen aus Helgoland II. - Hedwigia 77, $7-10$.

South, G. R., 1984. A checklist of marine algae of eastern Canada - second revision. - Can. J. Bot. 62, $680-704$.

South, G. R. \& Tittley, I., 1986. A checklist and distributional index of the benthic marine algae of the North Atlantic Ocean. Huntsman Marine Laboratory and British Museum (Natural History), St. Andrews and London, $76 \mathrm{pp}$.

Waern, M., 1958. Phycological investigations of the Swedish west coast. I. - Svensk bot. Tidskr. 52, 319-342.

Whittick, A., 1980. Antithamnionella floccosa (O. F. Müll.) nov. comb.: a taxonomic re-appraisal of Antithamnion floccosum (O. F. Müll.) Kleen (Rhodophyta: Ceramiaceae). - Phycologia 19, 74-79.

Wollny, R., 1881. Die Meeresalgen von Helgoland. - Hedwigia 20, 1-32.

Wollny, $R_{r}, 1886$. Algologische Mitteilungen. 5. Meeresalgen von Helgoland. - Hedwigia $25,132$.

Wynne, M. J., 1986. Porphyrostromium Trevisan (1849) vs. Erythrotrichopeltis Kornmann (1984) (Rhodophyta). - Taxon 35, 228-329. 